\title{
A PFE/IE - SPH joint approach to model landslides from initiation to propagation
}

\author{
Chuan Lin ${ }^{\mathrm{a}, \mathrm{b}}$, Manuel Pastor ${ }^{\mathrm{c}}$, Tongchun $\mathrm{Li}^{\mathrm{a}, *}$, Xiaoqing Liu ${ }^{\mathrm{a}}$, Chaoning $\operatorname{Lin}^{\mathrm{a}}$, Huijun $\mathrm{Qi}^{\mathrm{a}}$, \\ Taozhen Sheng ${ }^{\mathrm{a}}$ \\ ${ }^{a}$ College of Water Conservancy and Hydropower Engineering, Hohai University, Nanjing 210098, China \\ ${ }^{\mathrm{b}}$ College of Civil Engineering, Fuzhou University, Fuzhou 350108, Fujian, China \\ ${ }^{\mathrm{c}}$ Department of Applied Mathematics, ETSI Caminos, Universidad Politécnica de Madrid, Spain
}

Keywords:

Finite element model

Localized discontinuous deformation

Landslides

SPH

Depth-integrated models

\begin{abstract}
A B S T R A C T
Landslide is a complicated natural disaster that can be divided into multiple stages such as initiation and propagation. Researchers have been attempting to reveal the characteristics of each stage by practicing various modelling methods. This paper attempts to discover whether the combination of two popular approaches, including the Partitioned Finite Elements and Interface Elements method (PFE/IE) and the depth-integrated SPH model would bear a more reliable estimation. In the first stage, the PFE/IE method is practiced to investigate the triggering of slopes. The outcome from the first stage, including the contact force and the material parameters under limit state, are then utilized as the initial condition in the analysis of the subsequent propagation stage. In the propagation stage, the depth-integrated SPH model is used to explore the landslide propagation. Consequently, the SPH model is capable of dealing with large deformation problems that occur during the landslide movement process. Two benchmark tests are performed to verify the accuracy and feasibility of applying the hybrid model to study the landslide initiation. After the justification of the PFE/IE approach, it is then combined with the SPH model by an appropriate interpolation method. The presented PFE/IE-SPH joint approach is employed to evaluate the safety margin of a practical slope, as well as the potential effect region if the landslide occurs. The simulated result from the joint approach demonstrates its capability of providing references for the mitigation and protection measures.
\end{abstract}

\section{Introduction}

Landslides can cause extensive damage to human lives and economy. Since many events have indicated that after being initiated, landslides can be dramatically developed within a short period of time, even as short as a few minutes, it is of great importance to develop effective assessment tools for determining the stability of the considered slope and areas potentially influenced by the landslide.

A wide variety of conditions can destabilize slopes and trigger landslide. According to Terzaghi [1], landslide-triggering causes can be classified into external causes, which increase shearing stress (such as geometrical changes, loading slope crests, unloading slope toes, drawdown, etc.) and internal causes which reduce shearing resistance (such as progressive failure and creep, seepage erosion, weathering and fracturing, etc.). To better understand landslide causes, Popescu [2] summarized a short checklist containing four practical groups of landslide causes including ground conditions (such as plastic weak materials, jointed or fissured materials, adversely oriented mass discontinuities, etc.), geomorphological causes (such as tectonic uplifts, fluvial erosion of the slope toes, erosion of lateral margins, etc.), physical causes (such as intense and short rainfall periods, earthquakes, volcanic eruptions, etc.), and man-made causes (such as excavation of slopes or toes, irrigation, mining and quarrying, etc.). Many empirical and physical models have been developed to analyze the relation between precipitation and the initiation of landslides [3-5]. For example, Saito et al. [6] presented an empirical rainfall intensity and duration threshold for the initiation of shallow landslides in Japan. Other factors such as heterogeneous saturation degree and soil density are also of major concern in analyzing landslide stability. Since water saturation of slopes is a primary cause of landslide, Tsai et al. [7] introduced saturation degree to measure the effects of unit weight and unsaturated shear strength on rainfall-triggered shallow landslides. The strong relation between saturation degree and depth-averaged unit weight and unsaturated shear strength has been discussed in the literature. In this

\footnotetext{
* Corresponding author.
} 
paper, we have developed a fast-assessment tool for the determination of potential slope failures and possible run-out areas. For the sake of brevity, we have only considered the landslides triggered by material parameter reduction.

In the past few decades, with great development of computer technologies, numerical methods have rapidly been developed and become dominant in the analysis of slope stability [8-13]. These numerical methods can be generally classified into two categories: continuum-based methods (such as finite element method (FEM), finite difference method (FDM), boundary element method (BEM), etc.) and discontinuum-based methods (such as discrete element method (DEM), discontinuous deformation analysis (DDA), etc.). In the following, the performance and limitations of the above-mentioned methods are discussed.

FEM is almost the most widely applied numerical method in structural analyses. Since the publication of the work of Griffiths and Lane [8], FEM has been frequently used in the analysis of slope stability. In time, some modified approaches such as thin layer element method, interface element method, and spring element method have been developed for discontinuous deformation problems [14-17]. However, the application of FEM for practical slope cases is handicapped in discontinuous problems due to its requirement for small element sizes and conformable fracture paths. Considering the computational efficiency of FEM in nonlinear problems, BEM provides an alternative for solving contact problems by limiting nonlinearity only to the boundaries of the contacting bodies. Although BEM has the advantage of efficiency, it requires domain discretization treatments because non-linearity no longer permits partial differential equations to fully deform on element surfaces. DEM was first introduced for discontinuous and large-displacement problems. By employing explicit solutions for governing equations, DEM has a clear physical meaning, while the considered domain is usually limited because element size needs to be relatively small. As a representative of implicit DEMs, DDA method applies constant strain elements to reproduce blocks in the continuum parts and springs on the boundaries of the blocks to determine the relationships between relative displacements and forces [18-22]. Due to the difficulty of determining mechanical parameters for springs, there is the possibility of inaccurate simulations in transition from continuity to discontinuity.

Simulation of the initiation of slope slides in the presence of both continuity and discontinuity requires an approach capable of simultaneously taking into account both conditions. In recent years, hybrid numerical methods have become increasingly popular. A hybrid procedure for the analysis of rock dynamics has been developed by Jin et al. [23]. Since boundary element method can easily simulate the radiation damping of far field, it has been embedded into DEM procedure to allow the simulation of infinite and semi-infinite domains in hybrid systems. Therefore, a hybrid procedure combining the advantages of both methods can be used in the investigation of the effects of non-uniform input mechanism on discontinuous media with continuous far fields. Liu et al. [24] proposed a single-step method for the analysis of visco-elastic structures containing non-smooth contactable interfaces. In this method, nonlinear boundaries are handled by a twolevel algorithm providing a convenient and efficient solution for dynamic contact problems.

More recently, Zhang et al. [25] developed an interface stress element method for the analysis of anti-sliding stability of dams. The method decomposes the structure into discrete elements and interface elements which can naturally describe the features of discontinuous deformations including dislocations, openings or slips in the bedding planes of bedrocks providing better results than traditional FEMs. To study the uniaxial tensile behavior of concrete specimens, Du et al. [26] added Heaviside jump function into the common finite element approximation method for the simulation of discontinuities in cracked domains. The so-called extended finite element method can be applied in the investigation of the fracture of concrete specimens without any re-meshing treatments. Huang [27] directly coupled local discontinuous Galerkin and natural boundary element methods to solve a series of interface problems. In his work, an artificial boundary of spherical surfaces was applied in addition to coupled discrete primal formulations on the bounded domain. Also, the performance of the method in dealing with local discontinuities was demonstrated by several numerical examples. A DDA-FEM coupled method was developed by Sun et al. [28], using interior penalty Galerkin (IPG) method to improve the accuracy of DDA through discretizing blocks into discontinuous elements. In this method, a mixed strategy is used to assemble simultaneous equilibrium equations where the advantages of IPG method such as lack of locking, low computational cost, and great flexibility in meshing are highlighted.

An interactive method, called partitioned finite elements and interface elements (PFE/IE), has been developed by Li et al. [29] specifically for the analysis of stability in local discontinuous problems. The applicability of PFE/IE in the analysis of slope stability in both static and dynamic problems was subsequently proven in references [30,31].

Although hybrid methods provide reasonable solutions for the landslide stability problems, the simulation of the whole process including the initiation, mass movement and accumulation of landslides by only one single numerical approach is difficult $[32,33]$. Being of the Lagrangian description and "mesh-free", smoothed particle hydrodynamics (SPH) method is very capable of dealing with large deformations appearing in the propagation of landslides and therefore has been widely applied in relevant problems [34-37].

In this paper, the feasibility of using hybrid methods to assess slope stability has been investigated. The obtained ultimate state was employed to estimate the initiation state of landslide mass after triggering. Herein, hybrid method and depth-integrated SPH model were coupled for the simulations of contact force over failure surface and reduced material parameters. After the verification of the proposed method through benchmark tests, the coupled model was employed to analyze a practical slope case in the southwest of China. Furthermore, the influenced regions after landslide were estimated which provided a means for mapping hazardous areas to provide effective mitigation designs.

The remaining of the paper is organized as follows: in Section 2, a brief review of the hybrid method, depth-averaged SPH model, and their combination method are presented. Subsequently, two benchmark tests are performed to validate the performance and accuracy of the proposed hybrid model in Section 3. Finally, in Section 4, the potential hazards of an unstable slope are evaluated using the proposed model which could provide quantitative guidelines for hazard and mitigation treatments.

\section{A brief introduction of the hybrid method and depth-integrated SPH model}

\subsection{A hybrid method of PFE/IE}

To deal with the discontinuous problems in engineering problems, the PFE/IE hybrid method decomposes the calculation domain into continuous and discontinuous parts. For the continuous part, the partitioned finite element method is used to calculate the block deformation. Regarding the discontinuous part, the interface element method is applied to solve the contact internal force on the contact boundary. The hypotheses of the model including the decomposition of considering domain, the small thickness assumption of interfaces, the artificial division of the displacement and the transmission of the contact state, etc. The interested reader can find more details in the reference [29].

As depicted in Fig. 1, a simplified discontinuous system in landslide problems can be decomposed into two parts: sliding mass $\Omega_{1}$ and base rock $\Omega_{2}$. In the figure, $\delta$ is the gap between the contact point pairs, $F$ the external force, $f$ the contact force, $\xi \eta \xi$ the local coordinate system, respectively.

For each block inside the system, there are two unknowns: the 

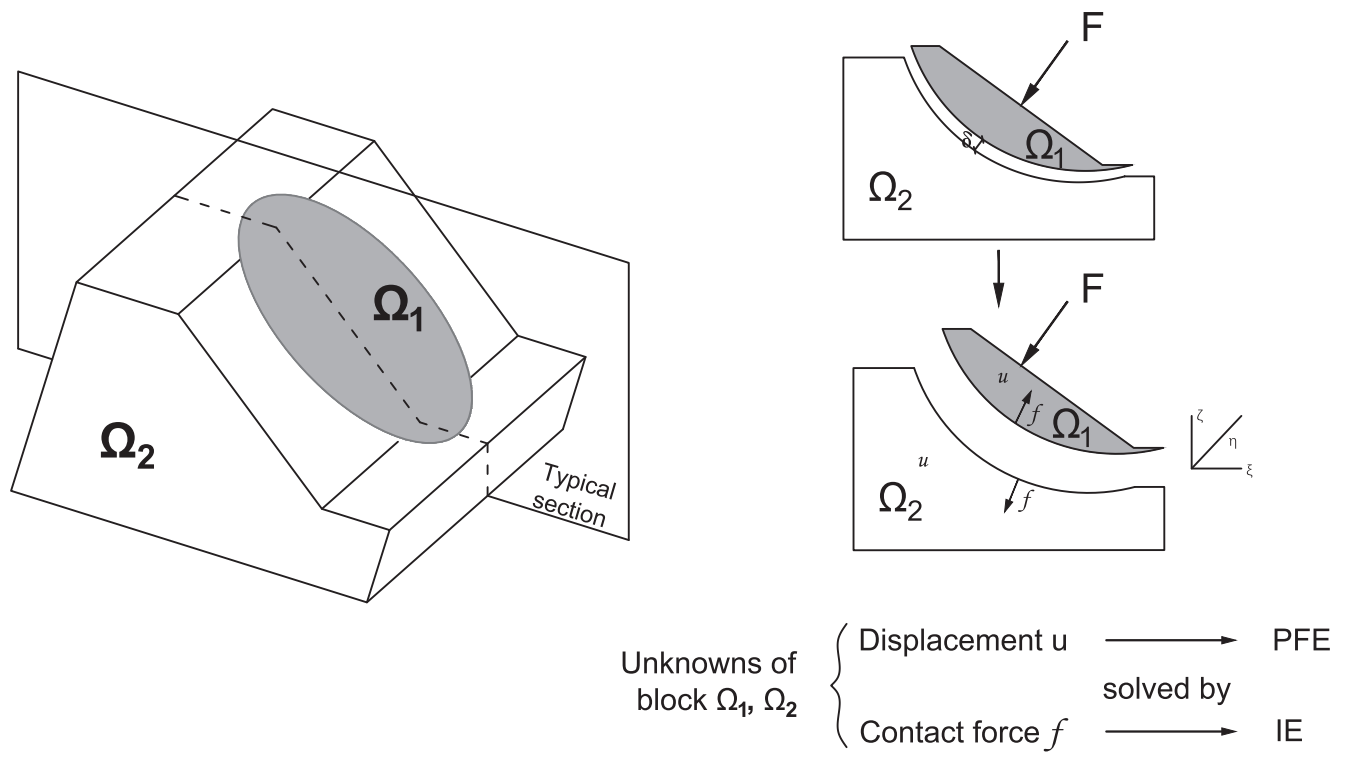

(a) A simplified landslide model

(b) Schematic diagram of the typical landslide section

Fig. 1. Schematic diagram of PFE/IE hybrid model.

contact force and the displacement on the interface boundary. Therefore, the solution of the governing equations requires to introduce a nonlinear relationship between these two unknowns. The nonlinear relationship can be described as:

a) The incremental displacement of each block node I $\left\{\Delta u_{t}\right\}_{i}$ including the incremental displacement of the deformable body $\{\Delta u\}_{i}$ and the rigid incremental displacement of the rigid body $\left\{\Delta u_{g}\right\}_{i}$ can be expressed as:

$\left\{\Delta u_{t}\right\}_{i}=\{\Delta u\}_{i}+\left\{\Delta u_{g}\right\}_{i}$

where the incremental displacement of the deformable body $\{\Delta u\}_{i}$ and the rigid incremental displacement of the rigid body $\left\{\Delta u_{g}\right\}_{i}$ can be solved by FEM and IE, respectively (see Fig. 1(b)).

b) Contact forces cause the block to deform.

c) Regarding the rigid body, Contact forces and external loads maintain a static balance at the centroid.

d) Block deformation can lead to the transformation of the contact force and the contact state.

The contact state of the interface is defined as three types, namely, open, closed and slip. For an arbitrary block, based on the aforementioned hypothesis, the displacement consists of two parts caused by the deformable body and the rigid body, respectively. For the incremental displacement of the deformable body, it can be solved by performing PFE for each block and the expression turns out to be

$\Delta u_{n}=\Delta \bar{u}_{n}+C \Delta f_{n}$

where $\Delta \bar{u}_{n}$ is the incremental displacement of the deformable body caused by total external load, $C$ the flexibility coefficient matrix, $f_{n}$ the increment of contact internal force at step $n$.

In terms of the rigid incremental displacement, for any node on the contact boundary, its rigid displacement involves translation and rotation can be determined by the kinematic relation and can be expressed as

$\Delta u_{g}=\omega_{i}^{k} \Delta \gamma_{n}^{i}$

where $\omega_{i}^{k}$ is the transform matrix of the node in the block.

If we introduce Eqs. (1) and (3) into Eq. (2), After some mathematical derivation it is possible to obtain the relational expression as:

$C^{k} \Delta f_{n}^{k}+\omega_{i}^{k} \Delta \gamma_{n}^{i}=\Delta u_{t n}^{k}-\Delta \bar{u}_{n}^{k}$ of which, $C^{k}$ is part of the total flexibility matrix relevant to node $k, \Delta \bar{u}_{n}^{k}$ the deformable incremental displacement due to the external load increment, $\Delta u_{t n}^{k}$ the total displacement increment at the current iterative step which is induced by both the external load increment and the contact force increment. It can be solved iteratively by the contact forces increment $\Delta f_{n}^{k}$ and the rigid displacement increment $\Delta \gamma_{n}^{i}$.

The Eq. (4) could be merged with Eq. (3), and therefore we have,

$\left[\begin{array}{cc}{[C]_{i}} & {\left[\omega_{\Gamma}\right]_{i}} \\ {\left[\omega_{\Gamma}\right]_{i}^{T}} & 0\end{array}\right]\left\{\begin{array}{l}\left\{\Delta f_{n}\right\}_{i} \\ \left\{\Delta \gamma_{n}\right\}_{i}\end{array}\right\}=\left[\begin{array}{cc}{[I]} & 0 \\ 0 & -\left[\omega_{\Omega}\right]_{i}^{T}\end{array}\right]\left\{\begin{array}{c}\left\{\Delta u_{t n}-\Delta \bar{u}_{n}\right\}_{i} \\ \left\{\Delta F_{n}\right\}_{i}\end{array}\right\}$

where subscript $\Gamma$ indicates the boundary of contact face and the dimension of $\left[\omega_{\Gamma}\right]$ is $\left.\left(p_{i} * \operatorname{dim}\right) \times[\operatorname{dim}-1) * 3\right]$, subscript $\Omega$ indicates the region of the block and the dimension of $\left[\omega_{\Omega}\right]^{T}$ is $[(\operatorname{dim}-1) * 3] \times\left(q_{i} * \operatorname{dim}\right)$.

More details about the hybrid method can be found in the relevant literature [29-31].

\subsection{Landslide propagation modelling: a depth-integrated SPH technique}

\subsubsection{Governing equations}

The governing equations for describing the movement of landslides are given by:

(a) Balance of mass

$\frac{d \rho}{d t}+\rho \operatorname{div} \boldsymbol{v}=0$

(b) Balance of linear momentum

$\rho \frac{d \boldsymbol{v}}{d t}=\operatorname{div} \sigma+\rho \boldsymbol{b}$

where $\rho$ is the density, $\boldsymbol{v}$ the velocity, $\sigma$ the total stresses, and $\boldsymbol{b}$ the gravity force.

These equations are then completed with rational constitutive or rheological models. Afterwards, the obtained kinematical relations can correlate strains and their rate to displacements or velocities.

Considering the average depths of landslides are usually over one order-of-magnitude smaller than their length or width, herein, we introduce depth-integrated model which has been widely applied by many researchers [35,36,38-43]

According to the reference system sketched in Fig. 2, the integration for sliding mass from the basal surface $Z$ to the surface of the landslide 

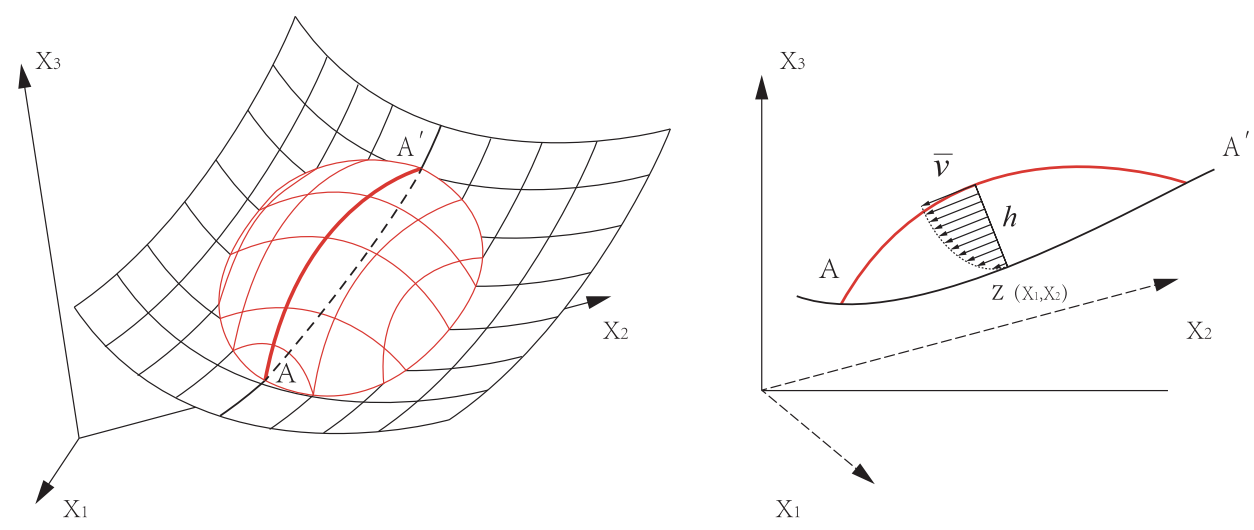

Fig. 2. Reference system, coordinates, and notation of depth-integrated model.
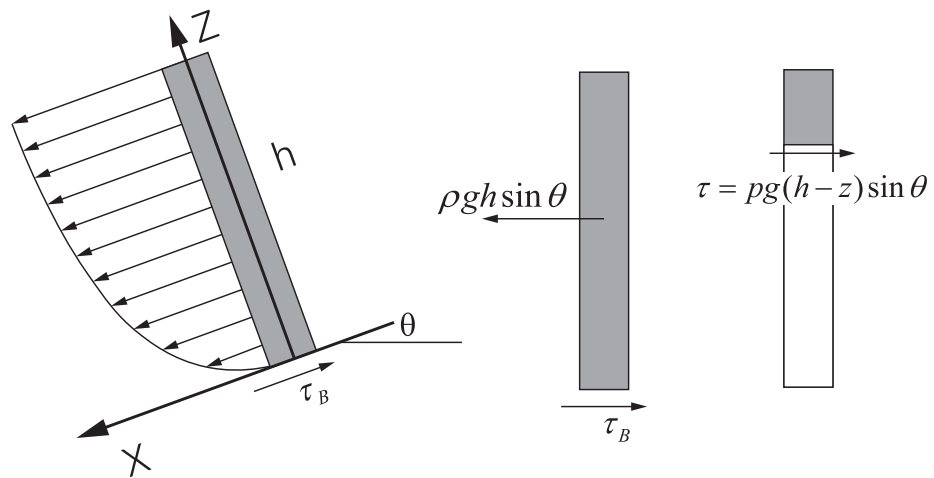

Fig. 3. The simple shear, infinite landslide model.

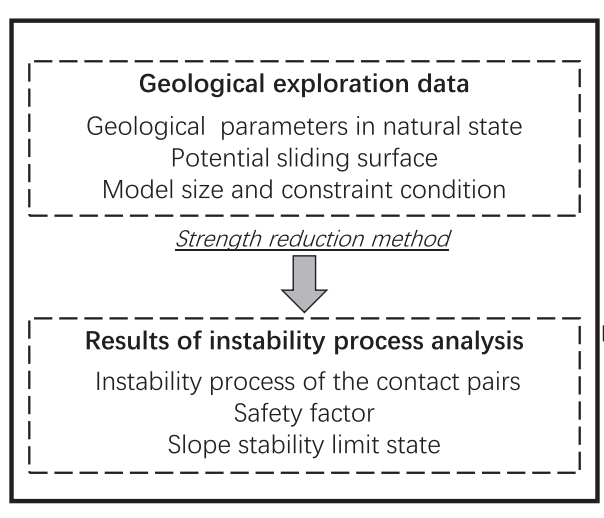

(a) PFE/IE hybrid method

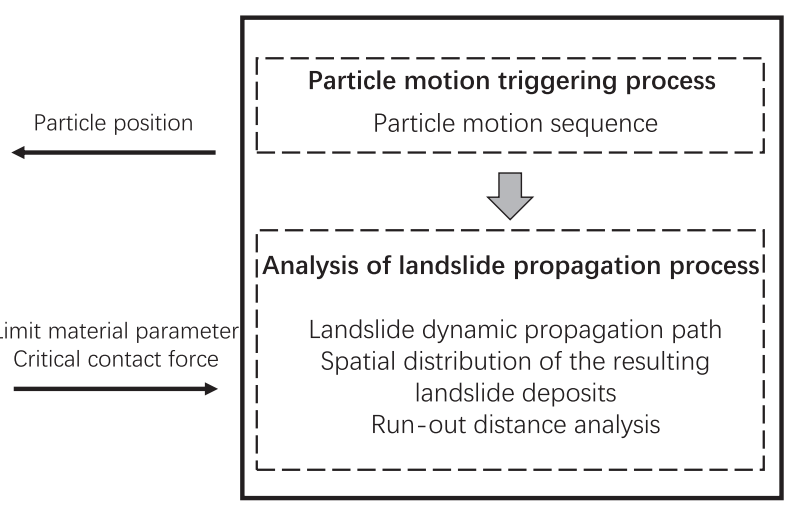

(b) Depth-integrated SPH method

Fig. 4. Schematic diagram of the combination of PFE/IE and SPH.

$Z+h_{s}$ can be implemented and results in:

(a) balance of mass

$\frac{d h}{d t}+h \frac{\partial \bar{v}_{i}}{\partial x_{i}}=0$

(b) balance of momentum

$h \frac{d \overline{\boldsymbol{v}}}{d t}=\operatorname{grad}\left(\frac{1}{2} b_{3} h^{2}\right)+b_{3} h \operatorname{grad} Z+\frac{1}{\rho} \tau_{B}$

where $\frac{d}{d t}$ is the "quasi-material derivative" defined by $\frac{\bar{d}}{d t}=\frac{\partial}{\partial t}+\bar{v}_{j} \frac{\partial}{\partial x_{j}}(j=1,2), h$ the depth, $\bar{v}$ the depth-averaged velocity, $Z$ the elevation of terrain, $\rho$ the density, $b_{3}$ the body force, $\tau_{B}$ the friction between soil and basal surface.

\subsubsection{A brief introduction of the rheology models}

As mentioned above, the governing equations need to be completed with a reasonable rheology medal. In depth-integrated model, the vertical structure of the flow is lost after integrating the balance of mass and momentum equations. For a given time step of the computations, the height of the landslide and the depth-averaged velocities are the only two known quantities. To retrieve the shear stress, the approach applied by most modelers consists of assuming that the current basal stress is the same as that in an infinite landslide. The main assumptions of infinite landslides are steady flows, no variations along the velocity direction and the velocity only depending on the $\mathrm{X}_{3}$ coordinate (Fig. 3).

The velocity profile and the basal shear stress can be obtained for a variety of 3D rheological models incorporating friction, viscosity, and cohesion.

For example, in the Bingham model - a pure cohesive viscoplastic 


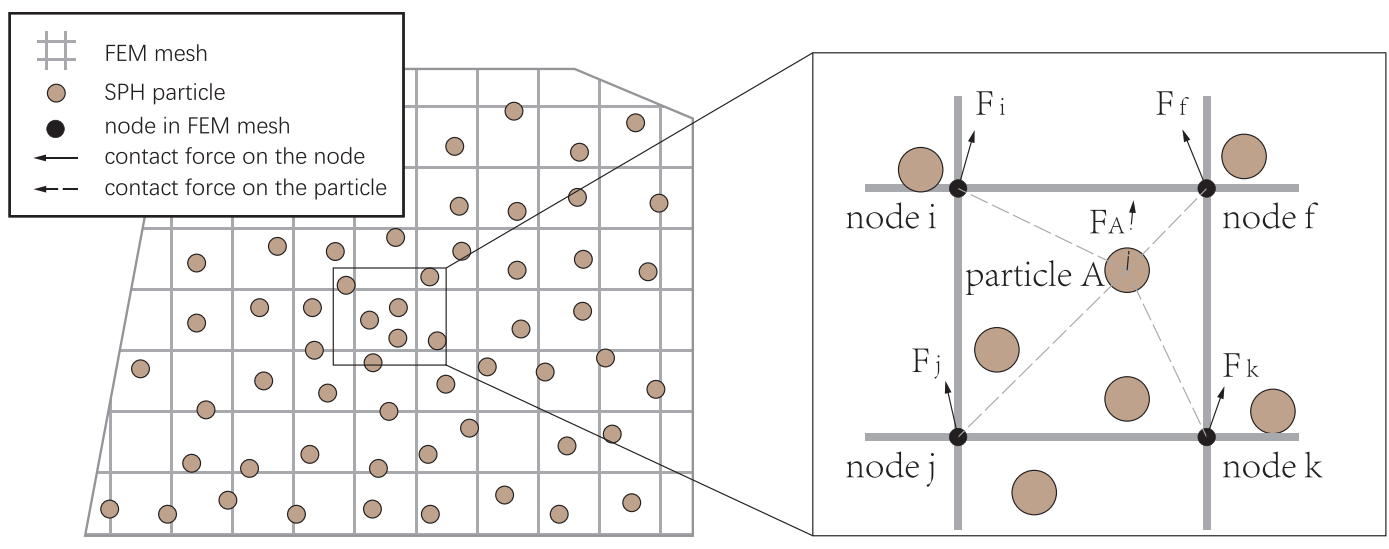

(a) Schematic of the SPH particle and PFE/IE mesh

(b) Interpolation method

Fig. 5. Illustration of the contact force transmission from PFE/IE to SPH.

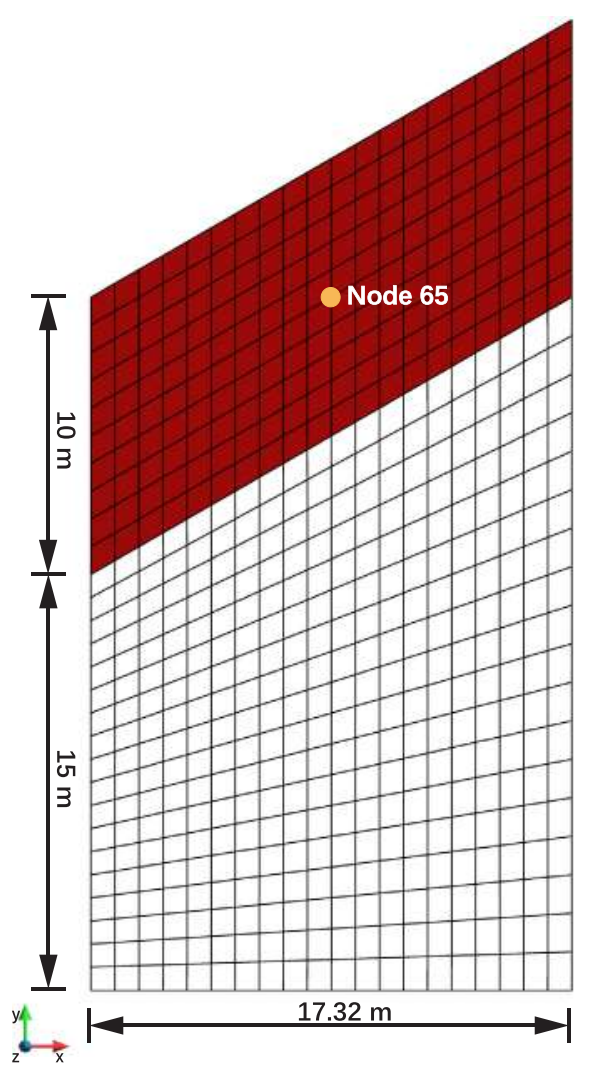

Fig. 6. Model details of the single contact surface test, including the position of the reference node and dimensions of the model.

fluid model - the basal shear stress is given by:

$\tau=\tau_{y}+\mu\left(\frac{\partial v_{1}}{\partial x_{3}}\right)$

where $\tau_{y}$ is the yield stress, and $\mu$ is the viscosity. After introducing the assumptions of the simple shear, infinite landslide model, the expression relating the averaged velocity to the basal friction can be expressed as:

$\bar{v}=\frac{\tau_{B} h}{6 \mu}\left(1-\frac{\tau_{y}}{\tau_{B}}\right)^{2}\left(2+\frac{\tau_{y}}{\tau_{B}}\right)$

The equation can be transformed into

$P_{3}(\eta):=\eta^{3}-(3+a) \eta+2=0$ where $a$ is a non-dimensional number and defined by $a=\frac{6 \mu \bar{v}}{h \tau_{y}}$, and $\eta$ is the ratio between the height of the constant velocity region to the total height of the flow and defined by $\eta=h_{P} / h$.

In order to obtain the basal shear stress, the roots of this third order polynomial have to be solved at each particle and time step, which requires high computational efforts. As an alternative approach, a simplified method proposed by Pastor et al. [44] is employed here, in which the third order polynomial approximation of equation is given by:

$P_{2}(\eta)=\frac{3}{2} \eta^{2}-\left(\frac{57}{16}+a\right) \eta+\frac{65}{32}$

The root can be obtained immediately once we know the value of the non-dimensional number $a$.

\subsubsection{SPH discretization}

The governing equations introduced in Section 2.2.1 can be discretized by various methods. In this paper, the SPH method where continuum media is represented by a set of particles, is used to discretize the above equations. In terms of the development of the SPH method, it was introduced by Lucy [45] and Gingold \& Monaghan [46] for astronomical modelling. Since then, it has been exported to other problems like hydrodynamics [47], avalanche propagation [35,48], and landslides [36,37,49], etc.

Within the system of SPH, any physical variable is approximated by the surrounding values, and the method is based on the identity

$\phi(x)=\int_{\Omega} \phi\left(x^{\prime}\right) \delta\left(x^{\prime}-x\right) d x^{\prime}$

where $\delta\left(x^{\prime}-x\right)$ is the Dirac's delta function centred at $x$. Here, the field function is approximated by the integral representation or termed as the kernel approximation in SPH models, and because of its smoothing effect the integral representation behaves as a weak form formulation.

The delta function can be approximated by a weighting function $W(x, h)$ fulfilling

$\lim _{h \rightarrow 0} W\left(x^{\prime}-x, \underline{h}\right)=\delta(x)$

where $\underline{h}$ is a parameter representing its decay.

The function $\phi(x)$ is approximated by

$\langle\phi(x)\rangle=\int_{\Omega} \phi\left(x^{\prime}\right) W\left(x^{\prime}-x, \underline{h}\right) d x^{\prime}$

The weighting function or kernel $W(x, \underline{h})$ is required to satisfy several conditions, such as the normalization condition, the Delta function property, and the compact condition, etc. In addition, the kernel needs to be a symmetric function of $\left(x^{\prime}-x, \underline{h}\right)$.

Regarding SPH modelling, several kernels have been presented in 


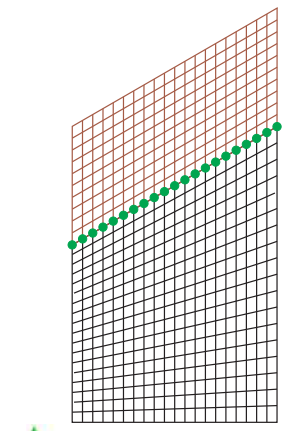

(a) 1.000

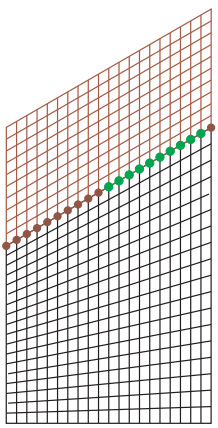

(b) 1.100

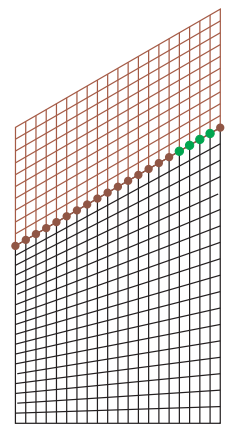

(c) 1.110

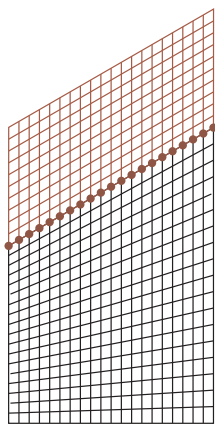

(d) 1.120

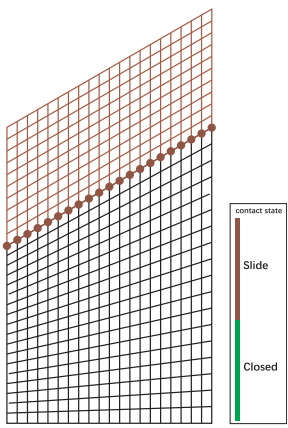

(e) 1.124

Fig. 7. The yielding procedure of contact pairs in the case of a single contact surface (under different reduction factors).

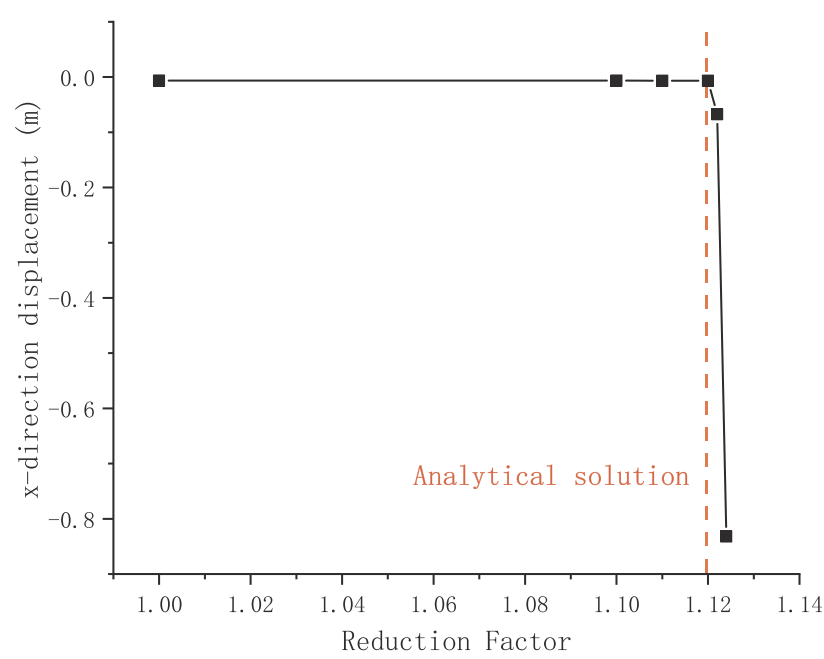

Fig. 8. Displacement of the reference point along X-direction in the case of a single contact surface.

the past. we use here the cubic spline proposed by Monaghan and Gingold [50] and Monaghan [51].

Taking into account the integral representation of the derivatives in $\mathrm{SPH}$, they are defined as:

$\left\langle\phi^{\prime}(x)\right\rangle=\int_{\Omega} \phi^{\prime}\left(x^{\prime}\right) W\left(x^{\prime}-x, \underline{h}\right) d x^{\prime}$

Concerning that the kernel has compact support, it results in:

$\left\langle\phi^{\prime}(x)\right\rangle=-\int_{\Omega} \phi\left(x^{\prime}\right) W^{\prime}\left(x^{\prime}-x, \underline{h}\right) d x^{\prime}$

Some operators of interest like the gradient of a scalar function, the divergence of a vector-valued function and the divergence of a tensorvalued function, can be approximated according to the integral representation process. Those operators are then introduced to acquire the kernel approximation (weak form) of the depth-integrated balance equations, the approximation is given by

(a) balance of mass

$\frac{d}{d t}\langle h\rangle+\langle h\rangle\left\langle\frac{\partial \bar{v}_{i}}{\partial x_{i}}\right\rangle=0$

If we write the equation at node $I$, and therefore we get

$\frac{d}{d t} h_{I}=h_{I} \cdot \int_{\Omega} \frac{1}{h_{J}} W^{\prime} \frac{\overline{\mathbf{v}}_{J} \cdot\left(x^{\prime}-x\right)}{r} d \Omega$

(b) balance of momentum

$\langle h\rangle \frac{d}{d t}\langle\overline{\boldsymbol{v}}\rangle=\left\langle\operatorname{grad}\left(\frac{1}{2} b_{3} h^{2}\right)\right\rangle+\left\langle b_{3} \operatorname{hgrad} Z\right\rangle+\left\langle\frac{1}{\rho} \tau_{B}\right\rangle$

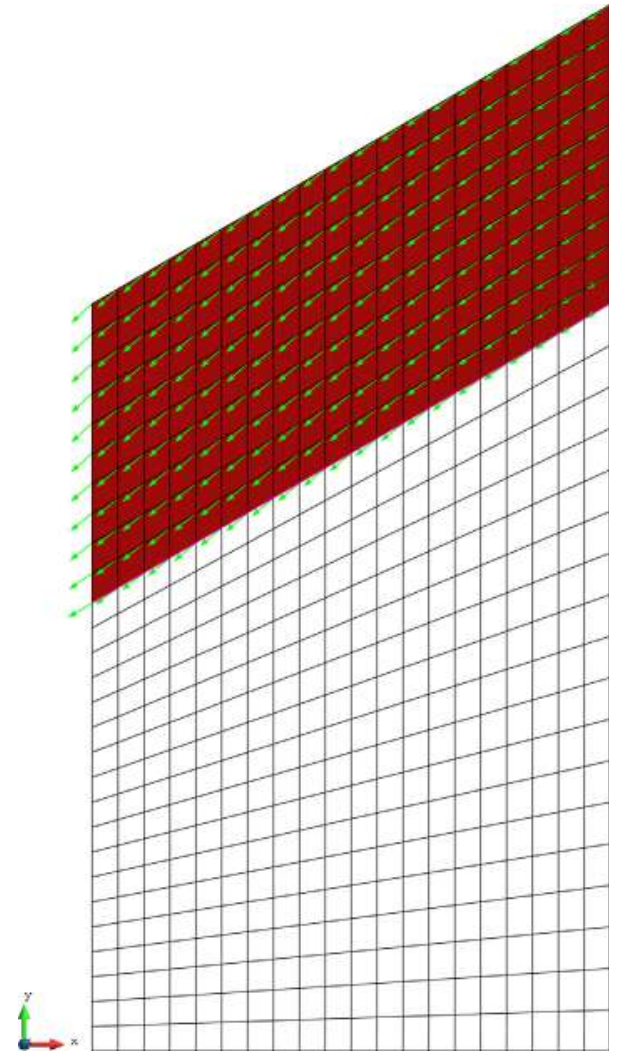

Fig. 9. Ultimate-state displacement vectors in the case of single contact surface.

Through the same process, we have the equation at node $I$ as:

$\frac{d}{d t} \overline{\mathbf{v}}_{I}=\frac{1}{h_{I}}\left\langle\operatorname{grad}\left(\frac{1}{2} b_{3} h_{I}^{2}\right)\right\rangle+b_{3} \operatorname{grad} Z+\frac{1}{\rho h_{I}} \tau_{B}$

And

$\frac{d}{d t} \overline{\boldsymbol{v}}_{I}=\frac{1}{h_{I}} \cdot \int_{\Omega} \frac{1}{2} b_{3} h_{J}^{2} \frac{1}{h_{J}} W^{\prime} \frac{x^{\prime}-x}{r} d \Omega+b_{3} \operatorname{grad} Z+\frac{1}{\rho h_{I}} \tau_{B}$

The kernel approximation is further approximated using particles in SPH. The SPH method introduces the concept of "particles", the concerning field variables in the domain are subdivided by them. We introduce a set of particles or nodes labelled with indexes $K=1 \ldots N$. Obviously, the level of approximation improves with increasing the nodes placed in the calculation region. Therefore, the strategic plan is to have more particles in a place where a large gradient occurs.

Considering the approximation of a function, since the information of the function is only available at the set of $\mathrm{N}$ nodes, the numerical integration technique can be used to evaluate the integral: 


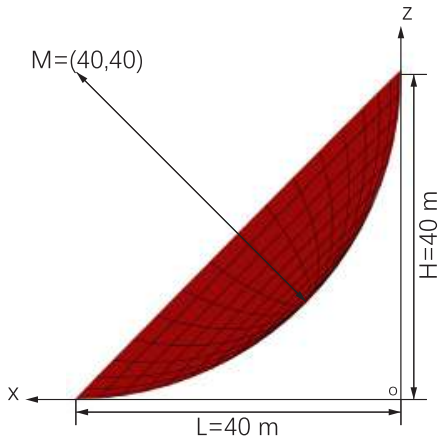

(a) Section

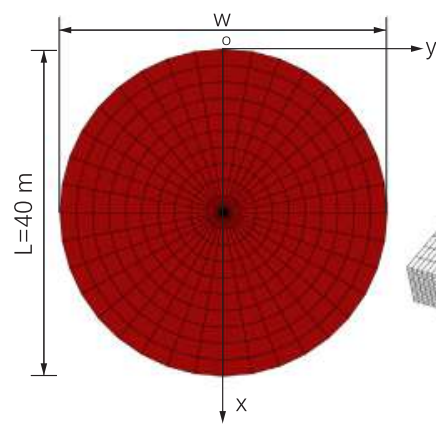

(b) Plane

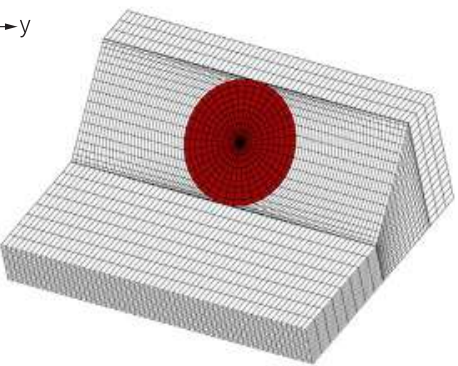

(c) Grid

Fig. 10. The model of ellipsoid landslide.

Table 1

Physical and mechanical parameters of ellipsoid landslide.

\begin{tabular}{|c|c|c|c|c|c|}
\hline \multirow[t]{2}{*}{ Material } & \multirow{2}{*}{$\begin{array}{l}\text { Density } \\
\left(\mathrm{kg} / \mathrm{m}^{3}\right)\end{array}$} & \multirow{2}{*}{$\begin{array}{l}\text { Elastic } \\
\text { modulus (MPa) }\end{array}$} & \multirow[t]{2}{*}{ Poisson's ratio } & \multicolumn{2}{|c|}{ Shear strength } \\
\hline & & & & $c(\mathrm{kPa})$ & $\varphi\left({ }^{\circ}\right)$ \\
\hline Contact surface & 2000 & 100 & 0.1 & 30 & 30 \\
\hline Bedrock & 2300 & 100 & 0.1 & - & - \\
\hline
\end{tabular}

$\phi_{I}=\left\langle\phi\left(x_{I}\right)\right\rangle_{h}=\sum_{J=1}^{N} \phi\left(x_{J}\right) W\left(x_{J}-x_{I}, \underline{h}\right) \Omega_{J}$

where we have used the sub-index " $\underline{h}$ " to represent the discrete approximation. The weights of the integration formula are $\Omega_{J}=m_{J} / \rho_{J}$ in which $\Omega_{J}, m_{J}$ and $\rho_{J}$ are the volume, mass and densities linked with node $J$.

This expression is the commonly used approximation form in SPH. In the situation we use the function $\phi$ to represent the density, we obtain:

$\rho_{I}=\sum_{J=1}^{N h} \rho_{J} W_{I J} \frac{m_{J}}{\rho_{J}}=\sum_{J=1}^{n} W_{I J} m_{J}$
Table 2

Comparison of the results obtained from different methods.

\begin{tabular}{llllll}
\hline Method & $\begin{array}{l}\text { Simplified } \\
\text { Bishop }\end{array}$ & 3D Spencer & $\begin{array}{l}\text { Simplified } \\
\text { Janbu }\end{array}$ & $\begin{array}{l}\text { 3D Sarma } \\
\text { [53] }\end{array}$ & $\begin{array}{l}\text { This } \\
\text { paper }\end{array}$ \\
\hline Safety factor & 1.30 & 1.34 & 1.25 & 1.48 & 1.45 \\
\hline
\end{tabular}

with $W_{I J}=W\left(x_{J}-x_{I}, \underline{h}\right)$.

For a node $I$, the fictitious volume $m_{I}$ moving with this node can be given by

$m_{I}=\Omega_{I} h_{I}$

where $\Omega_{I}$ is the $2 \mathrm{D}$ area associated to the node $I$.

Then, the kernel approximation of the balance Eqs. (20) and (23) can be further discretized using particle approximation method, and it results in:

$\frac{\bar{d}}{d t} h_{I}=-h_{I} \sum_{J} \frac{m_{J}}{h_{J}} \boldsymbol{v}_{J}^{T} \cdot \operatorname{grad} W_{I J}$

where we have introduced $\operatorname{grad} W_{I J}=\frac{W^{\prime}}{h} \frac{x_{I}-x_{J}}{r}$.

With respect to the balance of momentum equation, the discretized

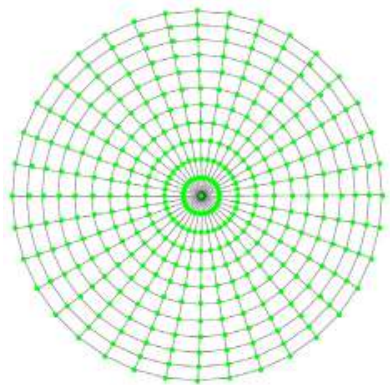

(a) 1.00

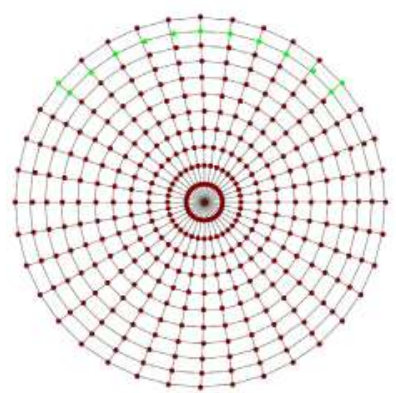

(d) 1.40

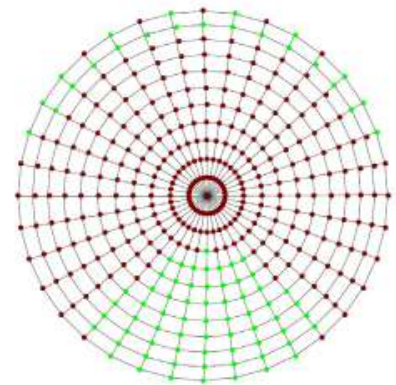

(b) 1.20

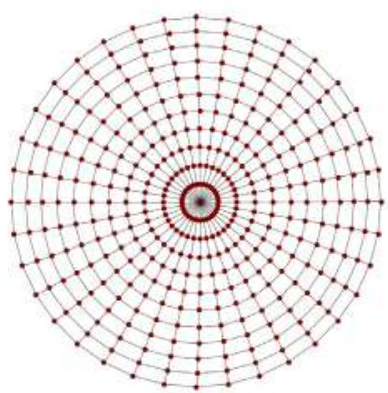

(e) 1.45

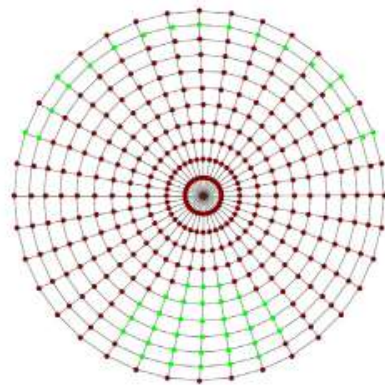

(c) 1.30

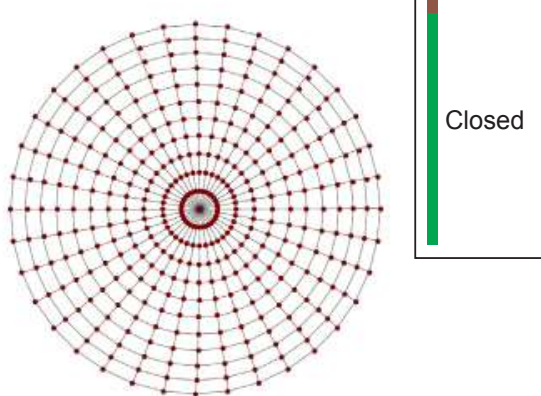

(f) 1.47

Fig. 11. The yield procedure of contact pairs in the case of an ellipsoid landslide (under different reduction factors). 


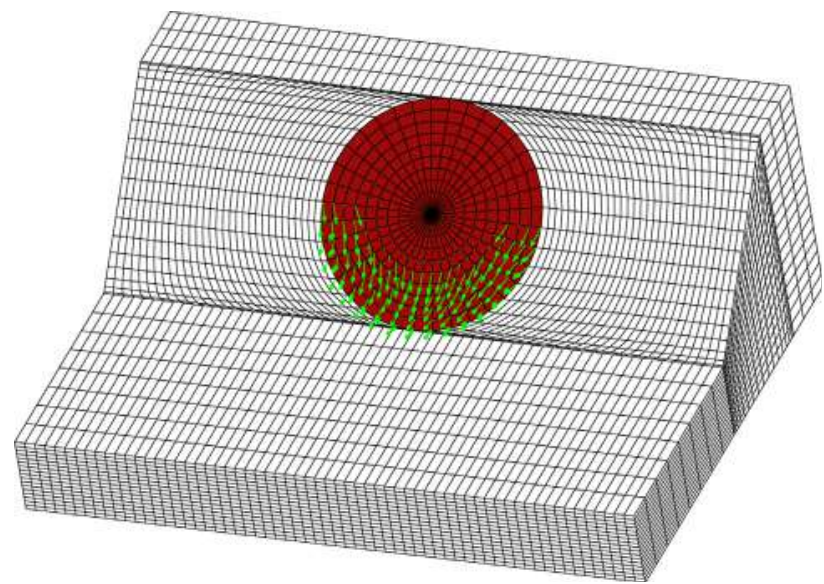

Fig. 12. Ellipsoid landslide model.

Table 3

Physical-mechanical parameters of the rock masses in Zhenzhuba slope.

\begin{tabular}{|c|c|c|c|c|c|}
\hline \multirow[t]{2}{*}{ Material } & \multirow{2}{*}{$\begin{array}{l}\text { Density }(\mathrm{kg} / \\
\left.\mathrm{m}^{3}\right)\end{array}$} & \multirow{2}{*}{$\begin{array}{l}\text { Elastic modulus } \\
(\mathrm{MPa})\end{array}$} & \multirow[t]{2}{*}{ Poisson's ratio } & \multicolumn{2}{|c|}{ Shear strength } \\
\hline & & & & $c(\mathrm{kPa})$ & $\varphi\left({ }^{\circ}\right)$ \\
\hline Sliding zones & 2200 & 15 & 0.4 & 16 & 17 \\
\hline $\begin{array}{l}\text { Landslide } \\
\text { body }\end{array}$ & 2300 & 20 & 0.35 & - & - \\
\hline Bedrock & 2500 & 2500 & 0.28 & - & - \\
\hline
\end{tabular}

form can be obtained as:

$\frac{\bar{d}}{d t} \overline{\mathbf{v}}_{I}=\sum_{J} m_{J} \frac{p_{I}+p_{J}}{h_{I} h_{J}} \cdot \operatorname{grad} W_{I J}+\boldsymbol{b}+\frac{1}{\rho h_{I}} \tau_{I}^{B}$

where $p=-\frac{1}{2} h^{2} b_{3}$ is the average pressure and the body force term $\boldsymbol{b}$ is given by $\boldsymbol{b}=b_{3}$ grad $Z$.

The interested reader can find more details in references [36,37,52].

\subsection{Combination of PFE/IE with SPH}

As stated above, the determination of the material parameters of potential landslides after initiation has always attracted the attention of researchers. Based on the available literature, back analysis is considered as an effective approach in acquiring reliable rheological parameter values. However, in the absence of relevant landslide events in nearby areas or enough on-site observation data, the application of such calibration-based approaches seems to be unrealistic. Since the simulation of landslide propagation is affected by the analysis of stability and critical stage judgment has been intensively investigated as a decisive factor in slope stability, the application of stability analysis methods to investigate limit stage and determine initial conditions for the following slope movement simulations can be promising in predicting potential landslide events.

In this paper, PFE/IE method, which has been proven to be an effective method for the analysis of landslide stability, has been coupled with strength reduction method to study the instability of slopes. As illustrated in Fig. 4, the proposed hybrid method was able to analyze slope failure and obtain essential information such as safety factor and slope limit state. Safety factor, i.e. reduction factor, can be adapted to determine material parameters under limit state, and limit contact force over sliding surface can provide more precise conditions for basal friction. Then, this information were input into depth-integrated SPH model for landslide propagation analysis.

Compared with reduced material parameters, limit state contact force requires further analysis. Firstly, we need to consider the calculation of bottom friction under the framework of depth-integrated models. In Section 2.2.2, we briefly introduce the basic hypotheses of the rheology models in depth-integrated system as well as polynomial approximation method by taking Bingham model as an example. For basal friction, when landslide body is stationary, which is the case in landslide triggering, the velocity of landslide mass is 0 . According to Bingham model, taking into account the expression of non-dimensional number $a$, we have:

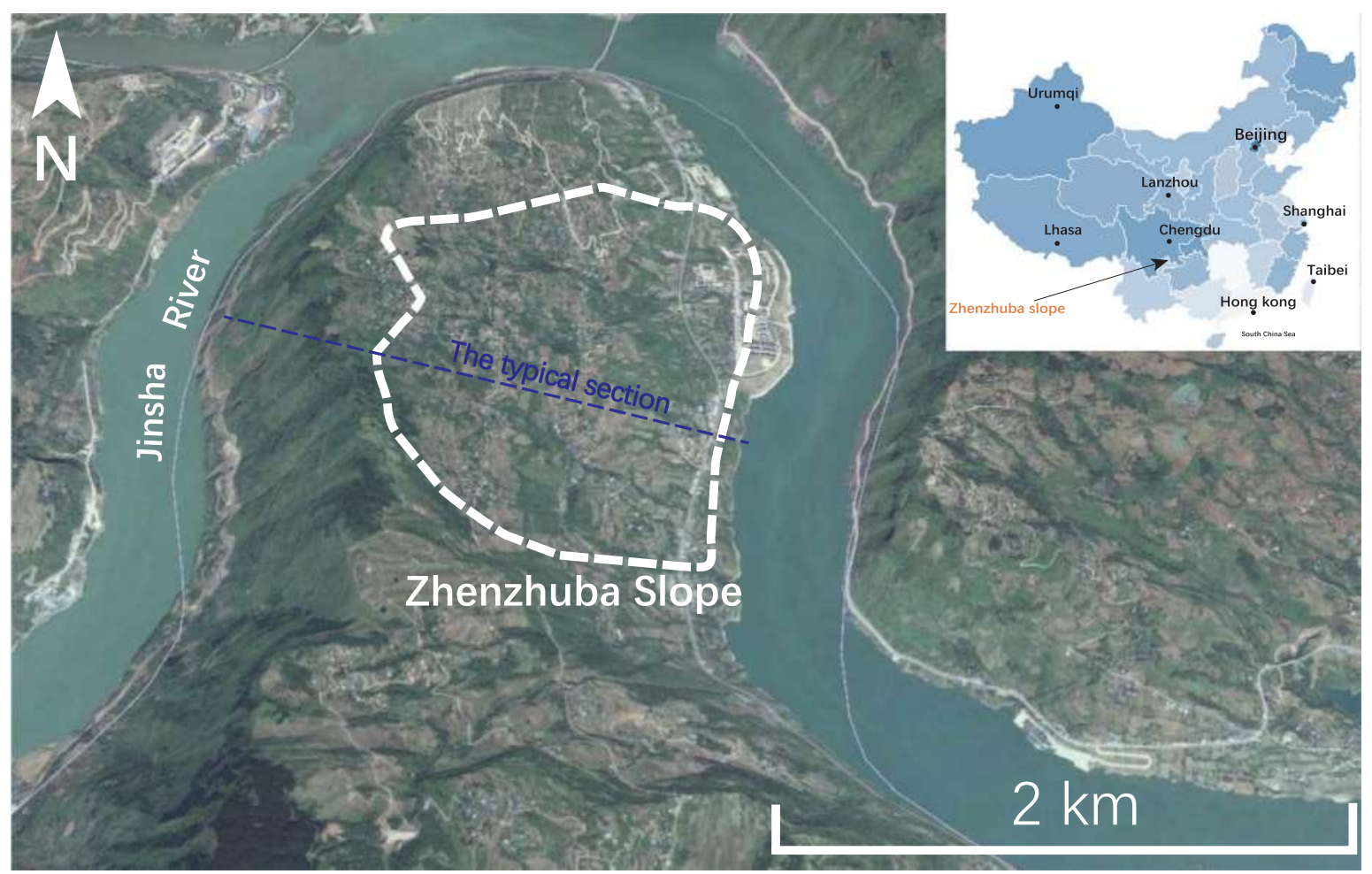

Fig. 13. Location of the Zhenzhuba landslide. 


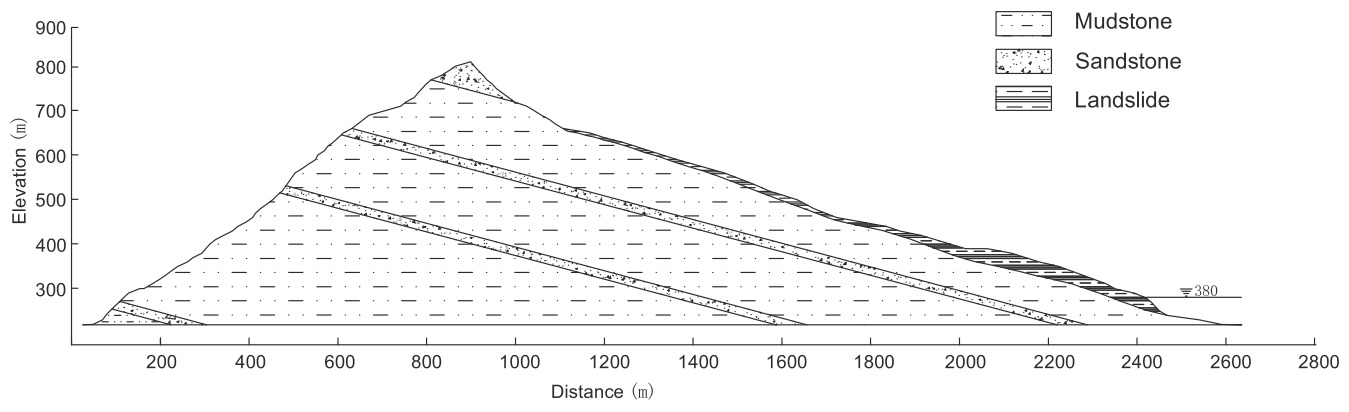

Fig. 14. Engineering geological profile of a typical section in Zhenzhuba slope.

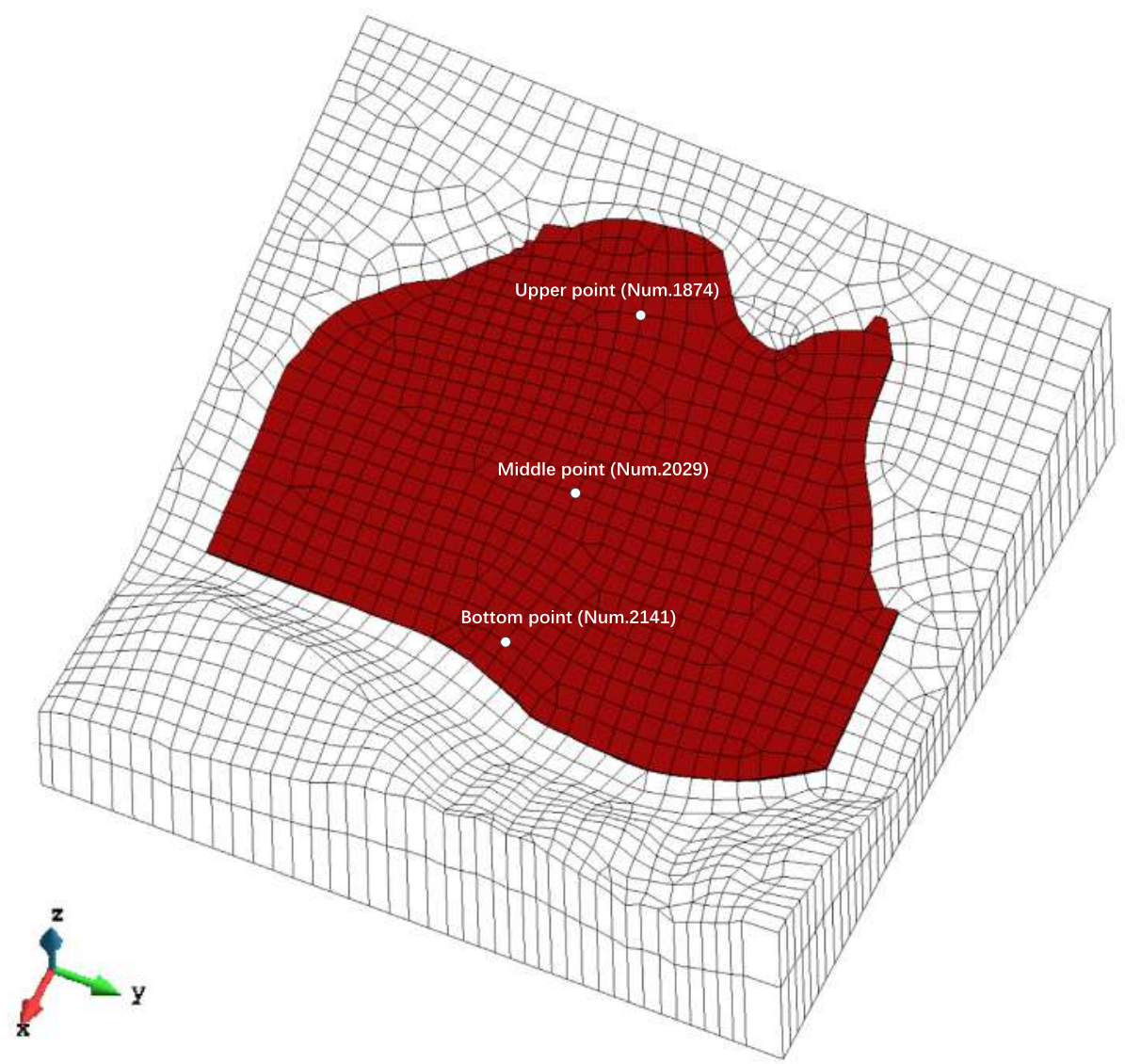

Fig. 15. The schematic diagram of Zhenzhuba slope.

Table 4

Displacements of reference node and contact states under difference reduction factors in Zhenzhuba slope.

\begin{tabular}{lllll}
\hline Reduction factor & \multicolumn{2}{l}{ Displacement in X (m) } & $\begin{array}{l}\text { Amount of the } \\
\text { failure pairs }\end{array}$ \\
\cline { 2 - 5 } & $\begin{array}{l}\text { Upper } \\
\text { point }\end{array}$ & $\begin{array}{l}\text { Middle } \\
\text { point }\end{array}$ & $\begin{array}{l}\text { Bottom } \\
\text { point }\end{array}$ & \\
\hline 1.10 & 0.0678 & 0.0790 & 0.0864 & $161 / 684$ \\
1.15 & 0.0706 & 0.0827 & 0.0903 & $234 / 684$ \\
1.20 & 0.0850 & 0.0989 & 0.1011 & $320 / 684$ \\
1.24 & 0.0969 & 0.1106 & 0.1161 & $684 / 684$ \\
1.26 & 0.9504 & 1.0508 & 1.1609 & $684 / 684$ \\
\hline
\end{tabular}

$a=\frac{6 \mu \bar{v}}{h \tau_{y}}=0$ considered to be 0 , which means all SPH particles in the domain are triggered and moved at once. Since the initiation of landslide over the sliding surface could be unsynchronized in real world, like what is observed in retrogressive landslides, we propose here to use the contact force obtained from PFE/IE method to determine basal friction in a more accurate manner. Once basal friction under stationary state is acquired, the "external force" part in the momentum Eq. (9) can be updated. Consequently, the sequence of particle motion can also be determined.

In Fig. 5, shows the transmission of contact force from PFE/IE mesh to SPH particles. Firstly, we traversed each SPH particle and determined their relative positions in PFE/IE grid. Then, since the contact force of element nodes was already known, the basal shear forces of SPH particles in each element (Fig. 5(b)) were obtained by applying an interpolation algorithm which is given by

which is out of the range of the approximation method considering region $a \in[0.001,1000]$. Therefore, in SPH model, basal friction is 


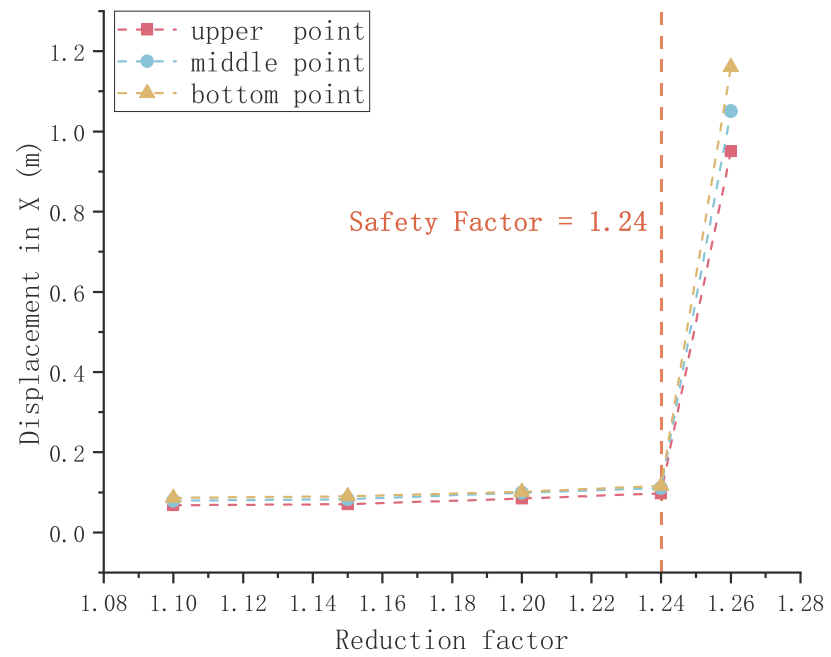

Fig. 16. The displacement of the monitoring points in the $\mathrm{X}$ direction.

$\phi_{i}=\frac{\sum_{j=1}^{n}\left(\frac{\phi_{j}}{d_{i j}}\right)^{m}}{\sum_{j=1}^{n}\left(\frac{1}{d_{i j}}\right)^{m}}$

where $\phi_{j}$ is physical quantity at mesh node $j, \phi_{i}$ is physical quantity at SPH particles $i, d_{i j}$ the distance between them and $m$ is set to 1 here.

\section{Benchmark tests}

In this section, two examples are illustrated to verify the robustness

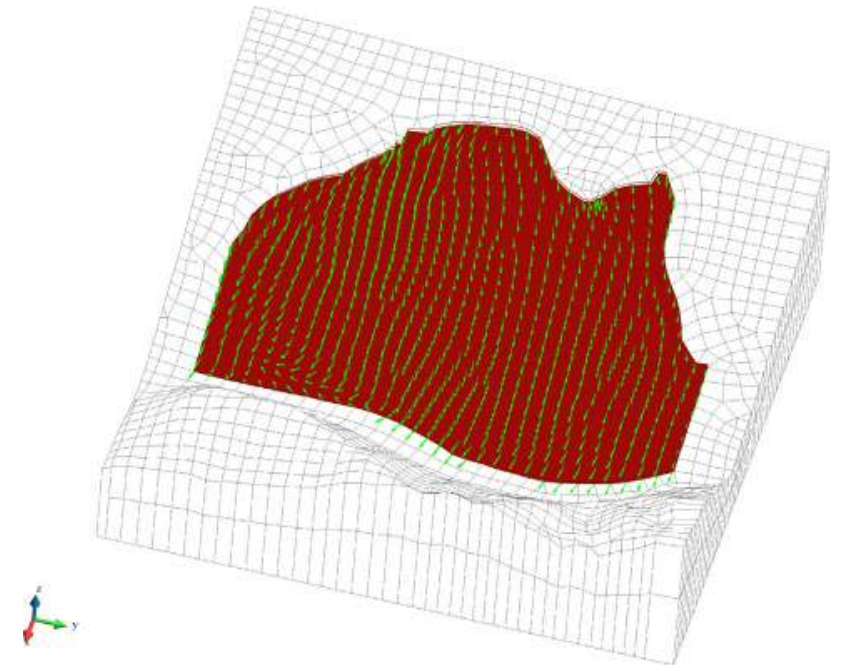

Fig. 18. Displacement vector when the slope is totally yielded and triggered.

and accuracy of the proposed hybrid model. These examples include analytical solutions and reference results obtained from literature for 2D and 3D problems.

\subsection{The case of a single contact surface}

In this case, a 2D finite element model of a parallelogram slope over a right trapezoidal base was considered, as shown in Fig. 6 . The model contained 560 elements and 609 nodes and both horizontal and vertical boundaries of the base rock were constrained during simulation.

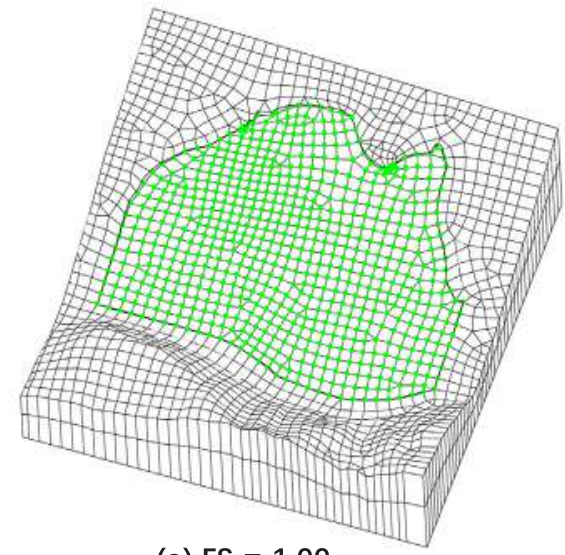

(a) $\mathrm{FS}=1.00$

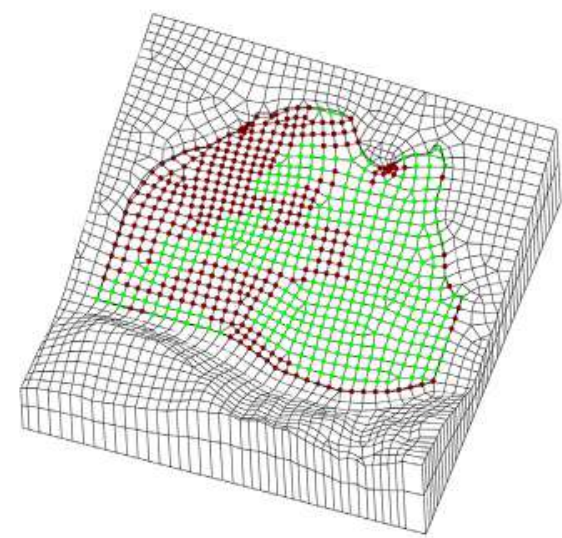

(c) FS $=1.20$

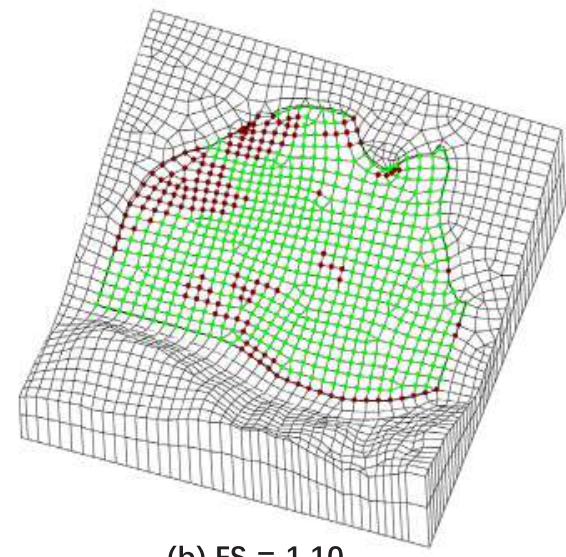

(b) $\mathrm{FS}=1.10$

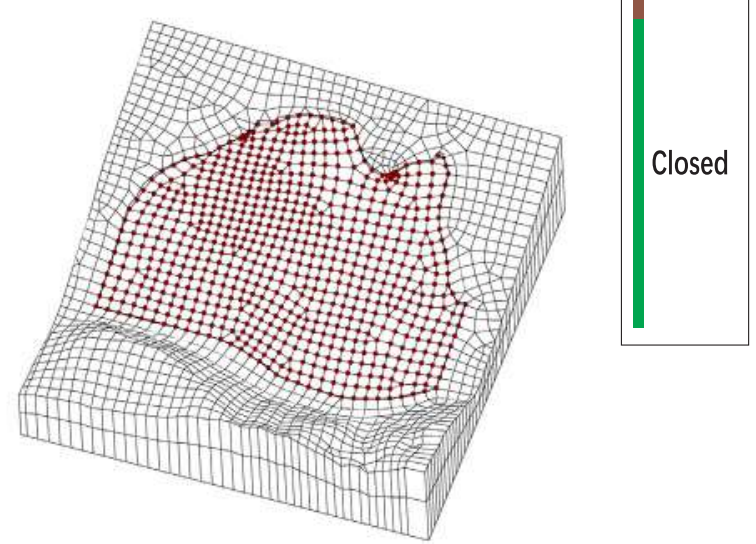

(d) FS $=1.24$

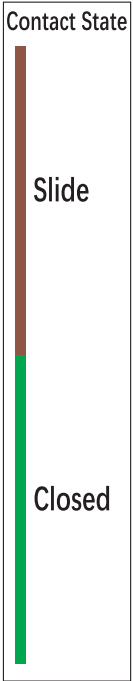

Fig. 17. The contact states of Zhenzhuba slope under strength reduction process. 


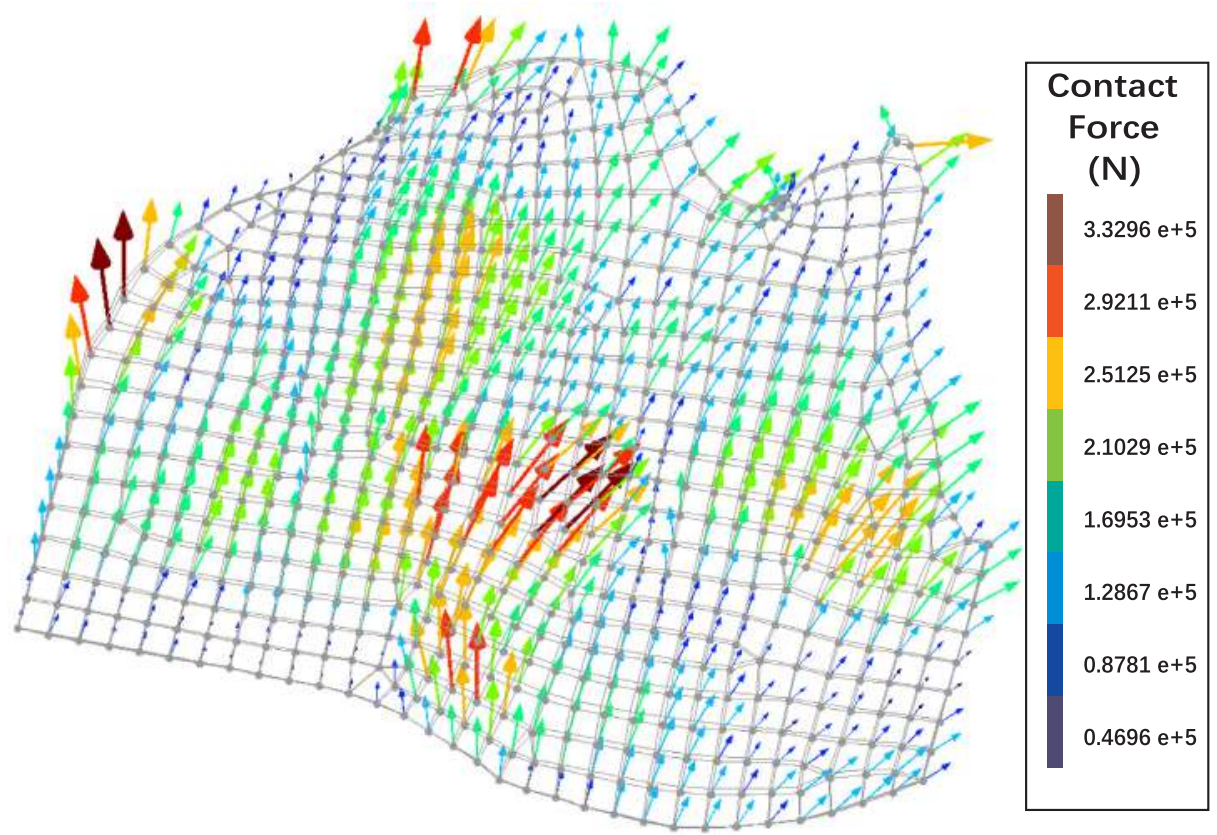

Fig. 19. Contact force vector along slip surface when landslide is triggered.
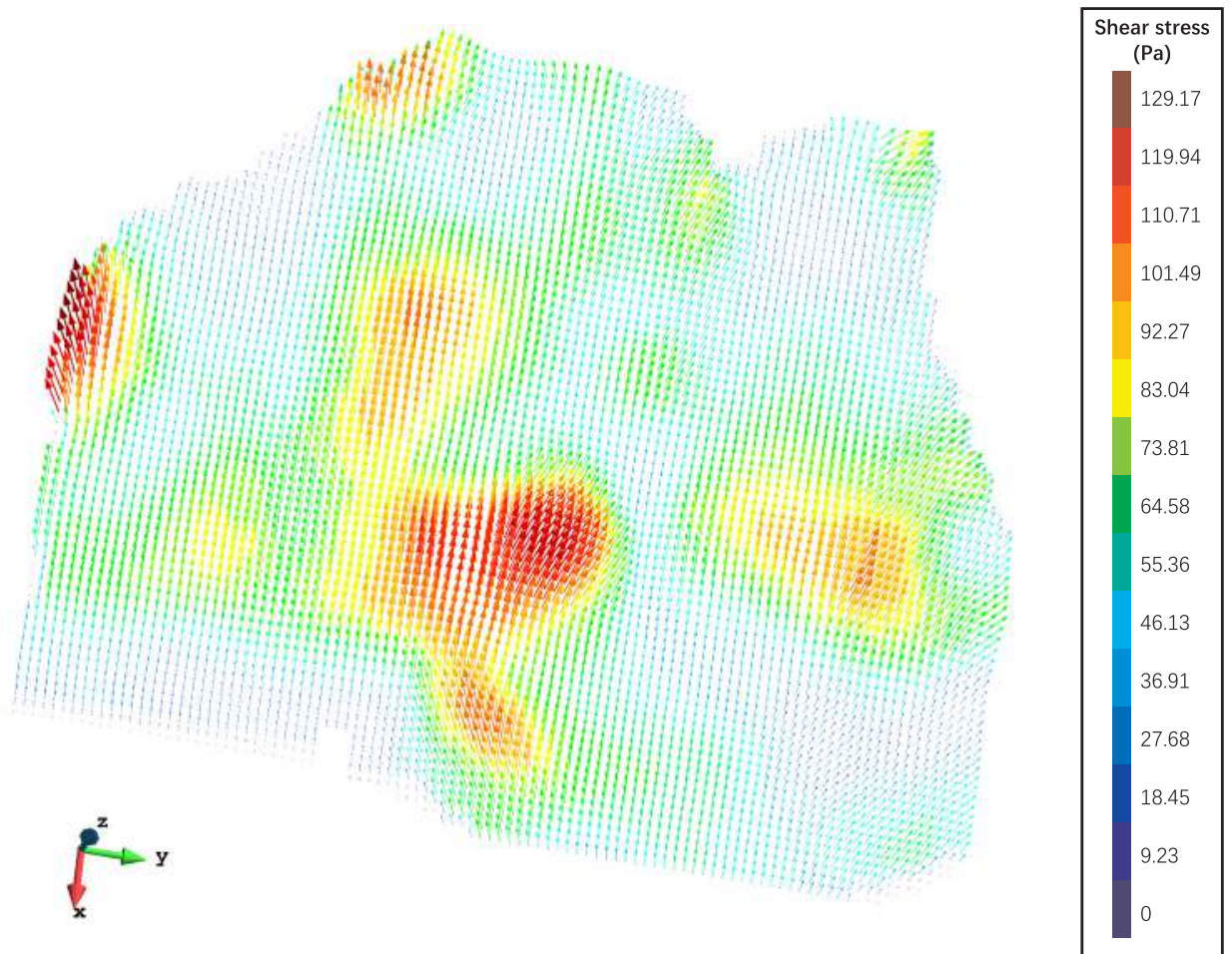

Fig. 20. Distribution of basal shear force of SPH particles.

Nonlinear iteration was limited and conducted only on joint pairs. Both slope and basal block were considered to be rigid. By applying the aforementioned hybrid method combined with strength reduction method, the development process involving the features of stress and deformation, rigid displacement and contact state on nodal pairs was obtained. The following assumptions were made in the simulation of this case: cohesion $C=10 \mathrm{kPa}$, frictional angel $\varphi=30^{\circ}$, and density $\rho=1960 \mathrm{~kg} \cdot \mathrm{m}^{-3}$. Since sliding surface was $30^{\circ}$ to the horizontal plane, the analytical solution of safety factor for this case was obtained to be 1.12 .

Displacement of reference node and the number of failure pairs in strength reduction process are shown in Figs. 7 and 8, respectively. As it can be seen, the displacement of the investigated node was almost unchanged in the beginning, while the amount of failure pairs was increased gradually and cohesion and friction angle were steadily reduced. During this process, the pairs located at slope toes were firstly yielded and then the failed zone was developed upwards, as can be seen in Fig. 7. Then, once the value of reduction factor reached 1.120, all nodal pairs started to slip (corresponding displacement vectors of the slope are given in Fig. 9). This can be also verified by the displacement curve illustrated in Fig. 8 where inflexion point occurred at the reduction factor of 1.120 . Therefore, the estimated safety factor of the 


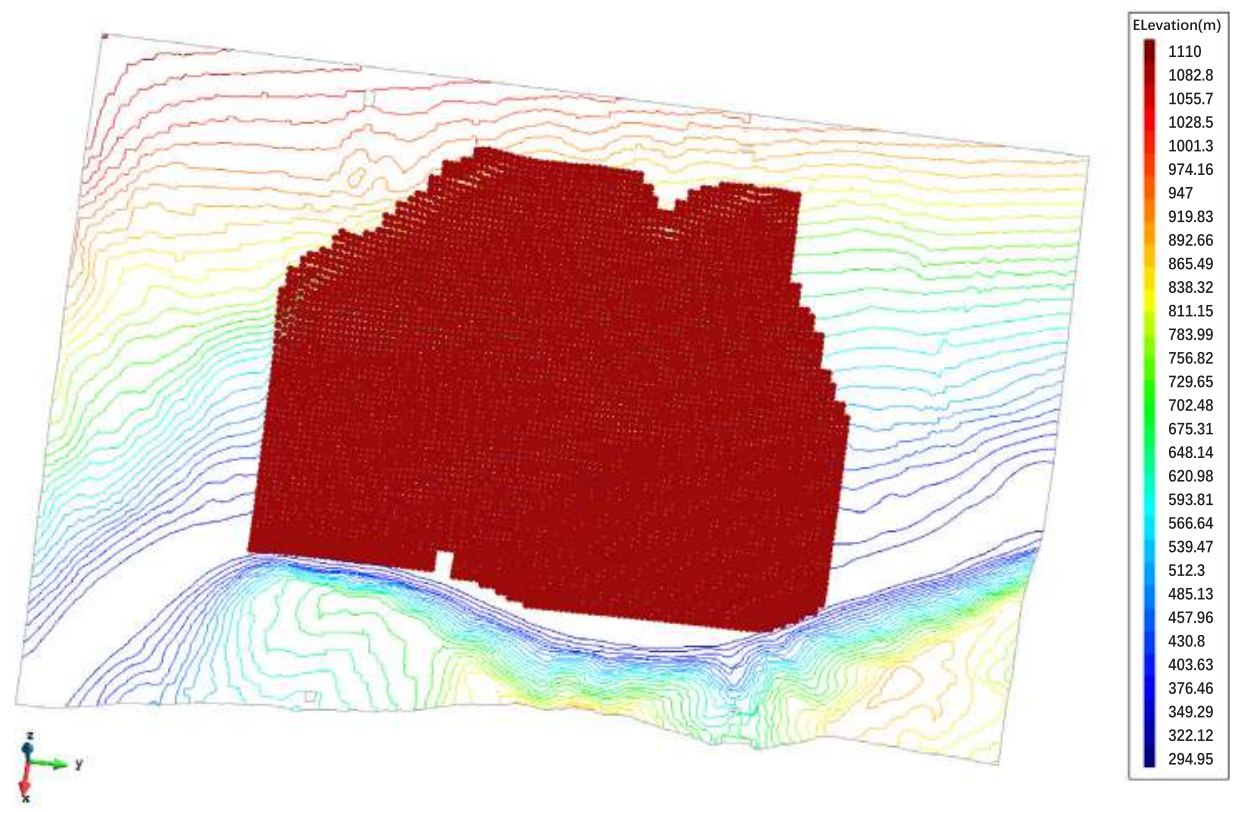

Fig. 21. Landslide particles over the topography model.

model was 1.12 which coincided with the theoretical solution.

\subsection{A case of an ellipsoid landslide}

A notable ellipsoid slope case was employed to evaluate the performance of the proposed model for 3D problems. Homogeneous rock slope was $40 \mathrm{~m}$ high with a slope angle of $45^{\circ}$, as shown in Fig. 10. The slip surface was defined as:

$\frac{\left(x-x_{0}\right)^{2}}{a^{2}}+\frac{y^{2}}{b^{2}}+\frac{\left(z-z_{0}\right)^{2}}{a^{2}}=1$

where $\left(x_{0}, z_{0}\right)$ are the center point coordinates of the spheres, and $a$ and $b$ are the rotational radii of the sphere. As indicated in Fig. 10, the radius of the central section was taken as $40 \mathrm{~m}$ and slip surface was assumed to pass through the toe and head of the slope; therefore, we had $a=x_{0}=z_{0}=40 \mathrm{~m}$. It should be noted that we had simplified the model by setting width $w$ equal to radius $r$. Therefore, the slope considered here was indeed a spherical cap slope.

In the established model, there were 39,098 nodes and 42,450 elements with 397 contact point pairs on the sliding surface. The physical properties of the slope are listed in Table 1. Contact states under different reduction factors are shown in Fig. 11. The figure shows that firstly, the contact pairs close to the backside of the slip surface started to slide and then failure region was developed toward slope toe and crest. To the best knowledge of the authors, two reasons could contribute to this phenomenon. First, the motion tendency of the slope was mainly determined by its rotational failure pattern where the down-slope movement of material occurred along a distinctive and deep surface. Secondly, landslide was assumed to be rigid during the simulation; therefore, for each contact pair, contact state mainly depended on the mechanical parameters and gradient of slip surface. Since mechanical parameters were maintained constant along slide surface, the backside contact pairs were more likely to start to move, owing to their relatively great slope gradients.

The obtained safety factor $(\mathrm{SF}=1.45)$ was compared with reference values obtained from other methods listed in Table 2. As can be observed in the table, the SF obtained from the proposed hybrid model was within the range of reference values from other limit equilibrium methods. Considering that limit equilibrium methods are generally more conservative than real situations, the estimated SF value from the hybrid model was considered to be reasonable. Finally, displacement vectors when landslide was triggered, are presented in Fig. 12.

\section{A case study of the Zhenzhuba landslide}

In this section, the proposed hybrid method is applied to assess the stability of Zhenzhuba slope. Moreover, the critical state of the slope including contact force and reduced material parameters are obtained. Simulation is performed using SPH method to investigate the propagation and final deposit distribution of potential landslide hazards (see Table 3).

As shown in Fig. 13, Zhenzhuba slope is located in Suijiang County of Yunnan Province, China about $68.7 \mathrm{~km}$ away from Xiangjiaba hydropower station. In terms of geology, the hill where the slope is located is of typical cuesta landform. The lithology of bedrock strata is grey-white and grey-green fine sandstone of J2s and the interbedded layer of dark purple-grey and green calcareous mudstones and argillaceous siltstone. The maximum elevation of the ridge is $940.8 \mathrm{~m}$ with an average slope of about $50^{\circ}$. The engineering geological structure of a typical section is presented in Fig. 14. According to geological report, the mechanical parameters for each stratum are listed in Fig. 5.

The established mesh model included 4436 elements and 6171 nodes as depicted in Fig. 15. In addition, three measuring points located at upper, middle and bottom parts of the slope were assigned to monitor slope displacements with various reduction factors. The periphery and the bottom of bedrock were constrained in the simulation.

Displacements along the $\mathrm{x}$-direction of monitoring points are summarized in Table 4. As shown in the table, displacements were increased gradually with the increase of reduction factor. Besides, for a given reduction factor, displacements were decreased from bottom to top. As can be seen in Fig. 16, the inflexion point of the displacement curve was obvious and the corresponding safety factor was taken as 1.24 .

The evolution of the contact states of the slope is illustrated in Fig. 17. When reduction factor was decreased to 1.10 , the left side of the upper part and the toe of the slope started to yield and slide. Then, half of the contact pairs were failed when the reduction factor reached 1.20. With further increase of reduction factor, failure region was gradually developed from the left side to other parts of the slope. Finally, all point pairs on the contact surface were slipped at the reduction factor of 1.24 . The displacement vector when the slope was completely yielded is demonstrated in Fig. 18. 


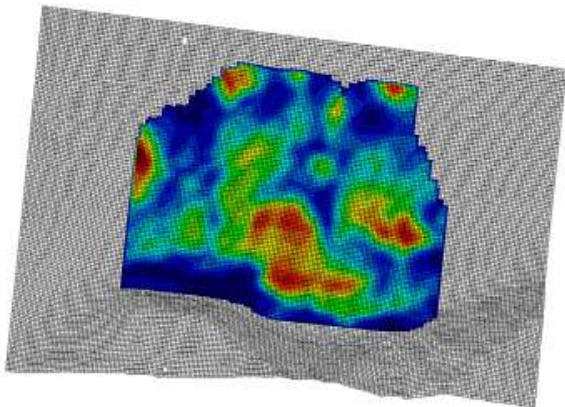

(a) $0.0 \mathrm{~s}$

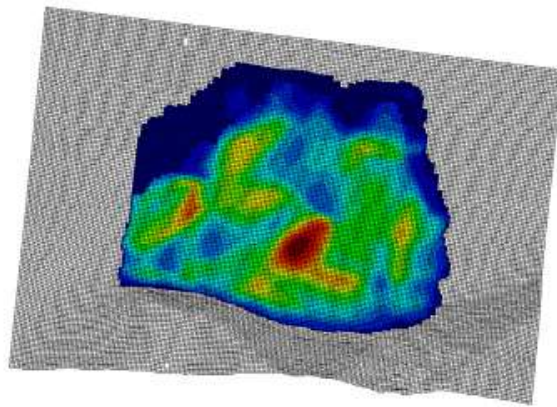

(c) $20.0 \mathrm{~s}$

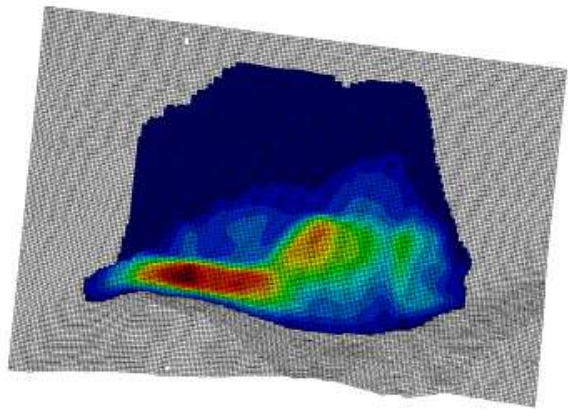

(e) $50.0 \mathrm{~s}$

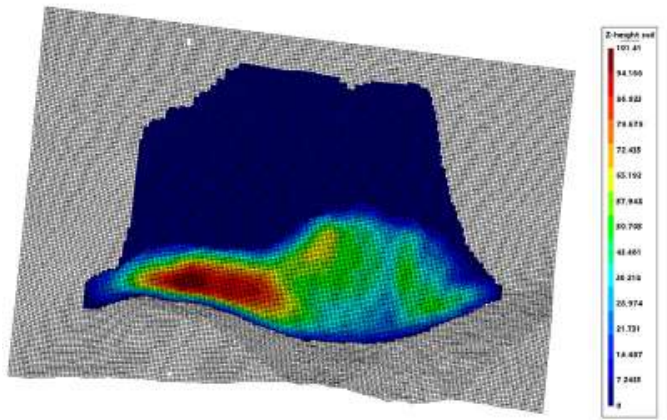

(g) $100.0 \mathrm{~s}$

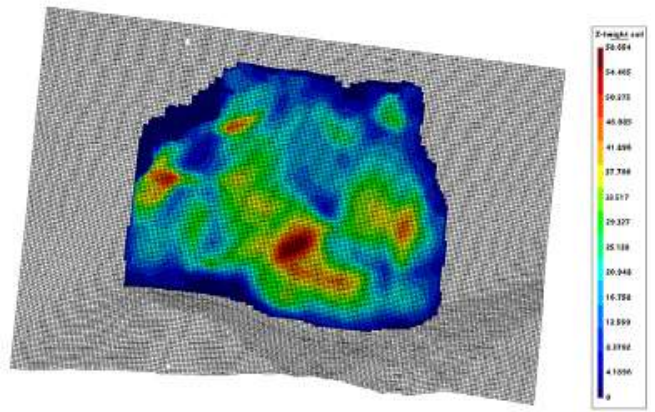

(b) $10.0 \mathrm{~s}$

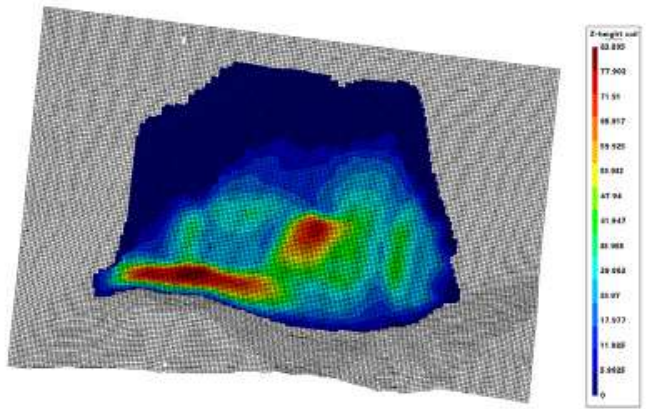

(d) $40.0 \mathrm{~s}$

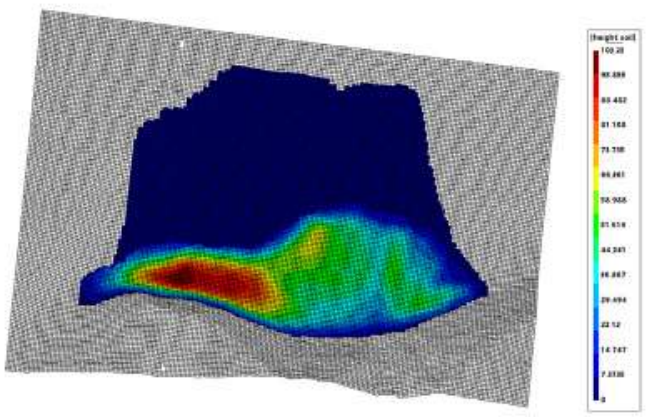

(f) $80.0 \mathrm{~s}$

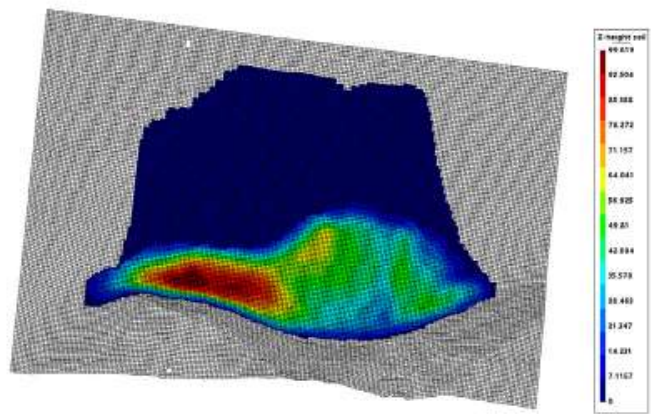

(h) Stationary State

Fig. 22. Time-lapse images of the simulation of Zhenzhuba landslide, colors refer to the height of sliding mass (m).

So far, we have evaluated the stability of Zhenzhuba slope, reduced mechanical parameters and contact forces when the slope was entirely yielded. According to geological reports, Bingham model was used here and reduced parameters were obtained at yield stress $\tau_{y}=12.9 \mathrm{kPa}$ and frictional angle $\phi=13.7^{\circ}$. The distribution of contact forces is presented in Fig. 19 in details. By applying the interpolation method introduced in
Section 2.3, the basal shear force of each SPH particle was acquired and used in SPH simulation (Fig. 20).

As shown in Fig. 21, 6496 landslide particles were created in SPH model. Numerical simulations were cast with computational duration of $400 \mathrm{~s}$. According to the estimated results, the sliding mass moved relatively fast in the beginning and then reached the central valley of the 


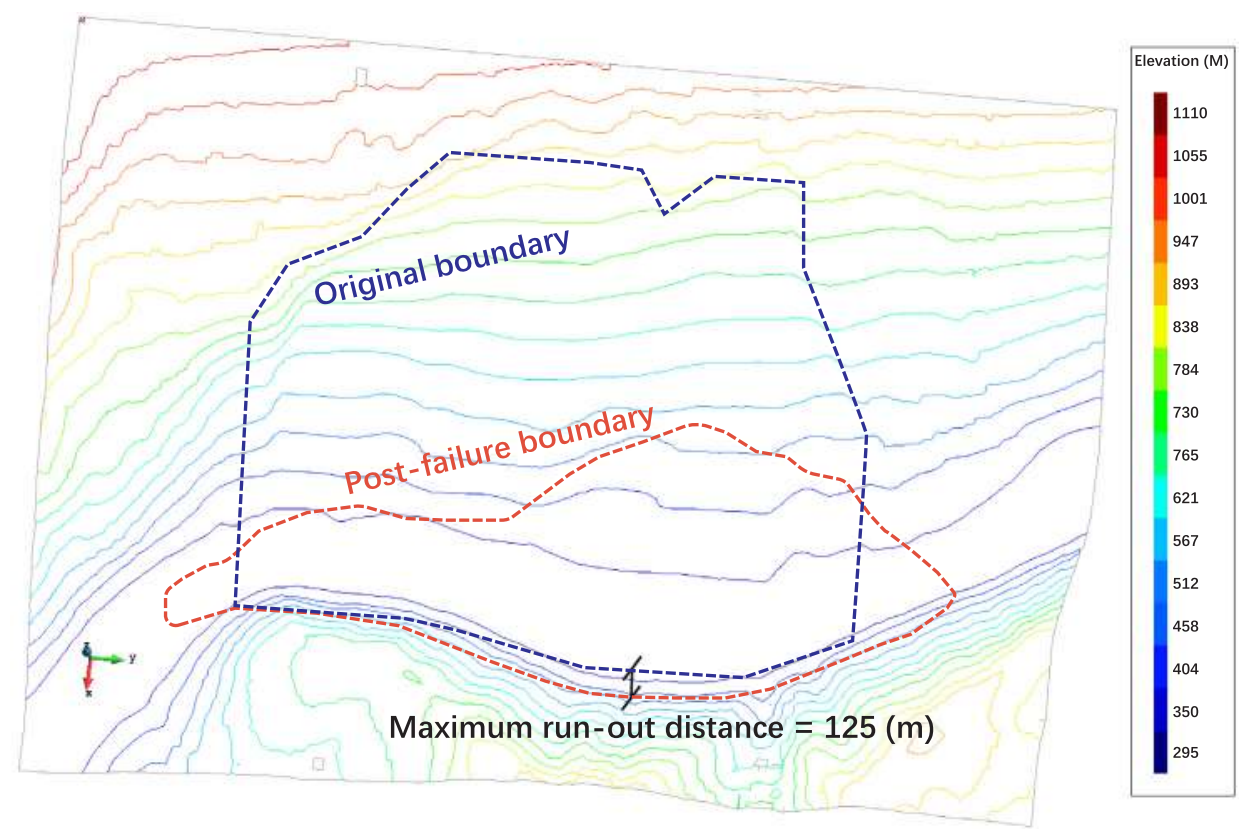

Fig. 23. Landslide track, and the maximum run-out distance.

terrain, as shown in Fig. 22(a-c). This process was accompanied by the energy dissipation of landslide; therefore, as evident in Fig. 22(d-g), the velocity of the sliding mass was sharply decreased as the materials gradually gathered on the left side of the slope toe. Finally, due to the dissipation of landslide kinetic energy, the landslide reached stationary state and deposited in the river course, as shown in Fig. 22(h). The maximum run-out distance of the landslide was about $125 \mathrm{~m}$ and appeared close to the left side of the slope front, (Fig. 23).

\section{Conclusion}

Landslides are common yet complex hazards. Because of their multiphysical nature, no single model can reproduce all phenomena existing in different stages of the event. Here, we have proposed a combined method of PFE/IE hybrid model and SPH technique for assessing possible landslide evolution scenarios in both initiation and propagation stages. In the initiation stage, PFE/IE hybrid model was employed to evaluate the stability of slope. Since non-linear iteration was limited on contact surface, hybrid model was able to effectively evaluate the stability and limit state of the slope including contact force over the sliding surface, and reduced material parameters were revealed by simulation results. Furthermore, to examine the accuracy of the proposed hybrid method, the model was tested against numerical examples available in the literature.

Then, the obtained limit state was applied to determine the trigger sequence of landslide in propagation stage, which was cast by SPH model. For a common depth-integrated SPH model, like the one used in the present work, the simplified expression of basal friction was related with averaged velocity which meant that basal shear force was neglected when slope was in stationary state. In other words, the slope slided simultaneously on the entire sliding surface. However, as we know from some practical landslide events such as some retrogressive landslides, the sliding sequence of different parts of landslide could be unsynchronized. Therefore, more detailed and accurate contact states determined by PFE/IE hybrid method can help us acquire the trigger sequence of landslide in SPH model, which was the reason for the combination of the two models.

Finally, the joint approach was applied to investigate the potential hazards of Zhenzhuba landslide. The initiation, propagation, and final deposition of Zhenzhuba landslide have been discussed in detail, which can be applied for hazard prevention in similar engineering problems. The main limitations of the presented numerical method are listed below:

(i) Only the slopes with apparent potential sliding surfaces have been discussed in the current work. For an arbitrary unstable slope without explicit possible failure surfaces, other techniques which can determine critical sliding surface under different loads can extend the scope of the present method.

(ii) We have only considered landslides triggered by material parameter reduction. Other causes such as intense rainfall, earthquake and human activities are also of great importance for understanding landslide initiation mechanism.

(iii) One of the advantages of the proposed joint method is that the triggering sequence of unstable slopes can be investigated by PFE/ IE model. Therefore, some practical events with comprehensive insitu data and experimental tests relating to regressive landslides can help validate the proposed method and improve its performance.

\section{Acknowledgement}

This work is supported by the Chinese National Key Research and Development Plan (Grant No. 2018YFC047102), and the Postgraduate Research \& Practice Innovation Program of Jiangsu Province (KYZZ16_0282).

The second author wishes to express his gratitude to the Spanish MINECO for the financial help granted (Project ALAS, BIA2016-76253P).

\section{References}

[1] Terzaghi K. Mechanism of landslides. Application of geology to engineering practice. Geol Soc Am 1950:83-123.

[2] Popescu ME. Landslide causal factors and landslide remediatial options. 3rd international conference on landslides, slope stability and safety of infra-structures: Citeseer. 2002. p. 61-81.

[3] Larsen MC, Simon A. A rainfall intensity-duration threshold for landslides in a humid-tropical environment, Puerto Rico. Geografiska Annaler: Series A Phys Geogr 1993;75(1-2):13-23.

[4] Hong Y, Hiura H, Shino K, Sassa K, Suemine A, Fukuoka H, et al. The influence of intense rainfall on the activity of large-scale crystalline schist landslides in Shikoku Island, Japan. Landslides 2005;2(2):97-105. 
[5] Crosta GB, Frattini P. Rainfall-induced landslides and debris flows. Hydrol Process: Int J 2008;22(4):473-7.

[6] Saito H, Nakayama D, Matsuyama H. Relationship between the initiation of a shallow landslide and rainfall intensity-duration thresholds in Japan. Geomorphology 2010;118(1-2):167-75.

[7] Tsai T-L, Chen H-F. Effects of degree of saturation on shallow landslides triggered by rainfall. Environ Earth Sci 2010;59(6):1285-95.

[8] Griffiths DV, Lane PA. Slope stability analysis by finite elements. Geotechnique 1999;49(7):653-4.

[9] Zienkiewicz O, Humpheson C, Lewis R. Associated and non-associated visco-plasticity and plasticity in soil mechanics. Geotechnique 1975;25(4):671-89.

[10] Zienkiewicz OC, Taylor RL, Taylor RL. The finite element method: solid mechanics. Butterworth-heinemann; 2000.

[11] Bui HH, Fukagawa R, Sako K, Wells J. Slope stability analysis and discontinuous slope failure simulation by elasto-plastic smoothed particle hydrodynamics (SPH) Geotechnique 2011;61(7):565-74.

[12] Jibson RW. Methods for assessing the stability of slopes during earthquakes-A retrospective. Eng Geol 2011;122(1-2):43-50.

[13] Zhao L-h, Cheng X, Li D-j, Zhang Y-b. Influence of non-dimensional strength parameters on the seismic stability of cracked slopes. J Mt Sci-Engl 2019;16(1):153-67.

[14] Buczkowski R, Kleiber M. Elasto-plastic statistical model of strongly anisotropic rough surfaces for finite element 3D-contact analysis. Comput Methods Appl Mech Eng 2006;195(37):5141-61.

[15] Desai CS, Zaman MM, Lightner JG, Siriwardane HJ. Thin-layer element for interfaces and joints. Int J Numer Anal Meth Geomech 2010;8(1):19-43.

[16] Gens A, Carol I, Alonso EE. An interface element formulation for the analysis of soil reinforcement interaction. Comput Geotech 1989;7(1):133-51.

[17] Günay E, Karel A. Composite design of the diesel engine cylinder with finite elemen analysis. Comput Struct 2000;75(2):117-34.

[18] Zhang Y, Xu Q, Chen G, Zhao JX, Zheng L. Extension of discontinuous deformation analysis and application in cohesive-frictional slope analysis. Int J Rock Mech Min Sci 2014;70:533-45.

[19] Peng X, Yu P, Zhang Y, Chen G. Applying modified discontinuous deformation analysis to assess the dynamic response of sites containing discontinuities. Eng Geol 2018;246:349-60.

[20] Peng X, Chen G, Yu P, Zhang Y, Guo L, Wang C, et al. Parallel computing of threedimensional discontinuous deformation analysis based on OpenMP. Comput Geotech 2019;106:304-13.

[21] Peng X, Chen G, Yu P, Zhang Y, Wang J. Improvement of joint definition and determination in three-dimensional discontinuous deformation analysis. Comput Geotech 2019;110:148-60.

[22] Yu P, Zhang Y, Peng X, Wang J, Chen G, Zhao JX. Evaluation of impact force of rock landslides acting on structures using discontinuous deformation analysis. Comput Geotech 2019;114:103137.

[23] Jin F, Wang G, Zhang C. A hybrid procedure of distinct-Boundary element for discrete rock dynamic analysis. Devel Geotech Eng 1998;83:313-20.

[24] Jingbo L, Shu L, Xiuli D. A method for the analysis of dynamic response of structure containing non-smooth contactable interfaces. Acta Mech Sin 1999;15(1):63-72.

[25] Zhang Q, Wang Z, Xia X. Interface stress element method and its application in analysis of anti-sliding stability of gravity dam. Sci China Technol Sci 2012;55(12):3285-91.

[26] Du X, Jin L, Ma G. Numerical modeling tensile failure behavior of concrete at mesoscale using extended finite element method. Int J Damage Mech 2014;23(7):872-98.

[27] Huang $\mathrm{H}$. The direct coupling of local discontinuous Galerkin and natural boundary element method for nonlinear interface problem in R3. Appl Math Comput 2015;262:232-48.

[28] Sun Y, Feng X, Xiao J, Wang Y. Discontinuous deformation analysis coupling with discontinuous Galerkin finite element methods for contact simulations. Math Probl Eng 2016;2016.

[29] Li T, Liu X, Zhao L. An interactive method of interface boundary elements and partitioned finite elements for local continuous/discontinuous deformation problems. Int J Numer Meth Eng 2015;100(7):534-54.

[30] Fan S, Li T, Liu X, Zhao L, Niu Z, Qi H. A hybrid algorithm of partitioned finite element and interface element for dynamic contact problems with discontinuous deformation. Comput Geotech 2018;101:130-40.

[31] Li T, He J, Zhao L, Li X, Niu Z. Strength reduction method for stability analysis of local discontinuous rock mass with iterative method of partitioned finite element and interface boundary element. Math Probl Eng 2015;2015:1-11.

[32] Pastor M, Herreros I, Merodo JF, Mira P, Haddad B, Quecedo M, et al. Modelling of fast catastrophic landslides and impulse waves induced by them in fjords, lakes and reservoirs. Eng Geol 2009;109(1):124-34.

[33] Zhou JW, Cui P, Yang XG. Dynamic process analysis for the initiation and movement of the Donghekou landslide-debris flow triggered by the Wenchuan earthquake. J Asian Earth Sci 2013;76(S1):70-84.

[34] Bonet J. Variational Formulation for the Smooth Particle Hydrodynamics(SPH) Simulation of Fluid and Solid Problems. Comput Methods Appl Mech Eng 2004;193(12):1245-56.

[35] Mcdougall S, Hungr O. A model for the analysis of rapid landslide motion across three-dimens. Can Geotech J. 2004;41(41):1084-97.

[36] Pastor M, Haddad B, Sorbino G, Cuomo S, Drempetic V. A depth-integrated, coupled SPH model for flow-like landslides and related phenomena. Int J Numer Anal Meth Geomech 2009;33(2):143-72.

[37] Pastor M, Yague A, Stickle MM, Manzanal D, Mira P. A two-phase SPH model for debris flow propagation. Int J Numer Anal Methods Geomech; 20174.

[38] Hutter K, Siegel M, Savage SB, Nohguchi Y. Two-dimensional spreading of a granular avalanche down an inclined plane Part I. theory. Acta Mech 1993;100(1-2):37-68.

[39] Savage SB, Hutter K. The dynamics of avalanches of granular materials from initiation to runout. Part I: analysis. Acta Mechanica 1991;86(1-4):201-23.

[40] Gray JMNT, Wieland M, Hutter K. Gravity-driven free surface flow of granular avalanches over complex basal topography. Proc Math Phys Eng Sci 1985;1999(455):1841-74.

[41] Laigle D, Coussot P. Numerical modeling of mudflows. J Hydraul Eng 1997;123(7):617-23.

[42] Pastor M, Quecedo M, Fernández Merodo J, Herrores M, Gonzalez E, Mira P.

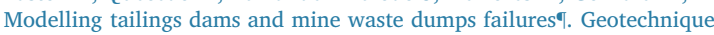
2002;52(8):579-91.

[43] Lin C, Pastor M, Yague A, Tayyebi SM, Stickle MM, Manzanal D, et al. A depth integrated SPH model for debris floods: application to Lo Wai (Hong Kong) debris flood of August 2005. Géotechnique 2018:1-59.

[44] Pastor M, Quecedo M, González E, Herreros M, Merodo JF, Mira P. Simple approximation to bottom friction for Bingham fluid depth integrated models. J Hydraul Eng 2004;130(2):149-55.

[45] Lucy LB. A numerical approach to the testing of the fission hypothesis. Astron $J$ 1977;82(82):1013-24.

[46] Gingold RA, Monaghan JJ. Smoothed particle hydrodynamics: theory and application to non-spherical stars. MNRAS 1977;181(3):375-89.

[47] Monaghan JJ, Kos A. Solitary Waves on a Cretan Beach. J Waterw Port Coastal Ocean Eng 1999;125(3):145-55.

[48] Manzanal D, Drempetic V, Haddad B, Pastor M, Stickle MM, Mira P. Application of a new rheological model to rock avalanches: an SPH approach. Rock Mech Rock Eng 2016;49(6):2353-72.

[49] Pastor M, Blanc T, Haddad B, Drempetic V, Sanchez Morles M, Dutto P, et al. Depth averaged models for fast landslide propagation: mathematical, rheological and numerical aspects. Arch Comput Methods Eng 2015;22(1):67-104.

[50] Monaghan JJ, Gingold RA. Shock simulation by the particle method SPH. J Comput Phys 1983;52(2):374-89.

[51] Monaghan JJ. Particle methods for hydrodynamics. Comput Phys Rep 1985;3(2):71-124.

[52] Pastor M, Martin Stickle M, Dutto P, Mira P, Fernandez Merodo JA, Blanc T, et al. A viscoplastic approach to the behaviour of fluidized geomaterials with application to fast landslides. Continuum Mech Thermodyn 2015;27(1-2):21-47.

[53] Li T-1, Wang Y-x, Deng H-k. An improved method for three-dimensional slope stability analysis. Chin J Geotech Eng-Chinese Ed 2003;25(5):611-4. 